\title{
Concurrent variation in oil and gas methane emissions and oil price during the COVID-19 pandemic
}

\author{
David R. Lyon ${ }^{1}$, Benjamin Hmiel ${ }^{1}$, Ritesh Gautam ${ }^{1}$, Mark Omara ${ }^{1}$, Katherine A. Roberts ${ }^{1}$, Zachary R. Barkley ${ }^{2}$, \\ Kenneth J. Davis ${ }^{2}$, Natasha L. Miles ${ }^{2}$, Vanessa C. Monteiro ${ }^{2}$, Scott J. Richardson ${ }^{2}$, Stephen Conley ${ }^{3}$, \\ Mackenzie L. Smith ${ }^{3}$, Daniel J. Jacob ${ }^{4}$, Lu Shen $^{4}$, Daniel J. Varon ${ }^{4}$, Aijun Deng ${ }^{5}$, Xander Rudelis ${ }^{6, a}$, Nikhil Sharma ${ }^{6}$, \\ Kyle T. Story ${ }^{6}$, Adam R. Brandt ${ }^{7}$, Mary Kang ${ }^{8}$, Eric A. Kort ${ }^{9}$, Anthony J. Marchese ${ }^{10}$, and Steven P. Hamburg ${ }^{1}$ \\ ${ }^{1}$ Environmental Defense Fund, 301 Congress Ave., Suite 1300, Austin, TX, USA \\ ${ }^{2}$ The Pennsylvania State University, University Park, PA, USA \\ ${ }^{3}$ Scientific Aviation, Boulder, CO, USA \\ ${ }^{4}$ Harvard University, Cambridge, MA, USA \\ ${ }^{5}$ Utopus Insights, Inc., Valhalla, NY, USA \\ ${ }^{6}$ Descartes Labs, Santa Fe, NM, USA \\ ${ }^{7}$ Stanford University, Palo Alto, CA, USA \\ ${ }^{8}$ McGill University, Montreal, Quebec, Canada \\ ${ }^{9}$ University of Michigan, Ann Arbor, MI, USA \\ ${ }^{10}$ Colorado State University, Fort Collins, CO, USA \\ ${ }^{a}$ now at: Google LLC, Mountain View, CA, USA
}

Correspondence: David R. Lyon (dlyon@edf.org)

Received: 10 November 2020 - Discussion started: 11 December 2020

Revised: 12 March 2021 - Accepted: 15 March 2021 - Published: 3 May 2021

\begin{abstract}
Methane emissions associated with the production, transport, and use of oil and natural gas increase the climatic impacts of energy use; however, little is known about how emissions vary temporally and with commodity prices. We present airborne and ground-based data, supported by satellite observations, to measure weekly to monthly changes in total methane emissions in the United States' Permian Basin during a period of volatile oil prices associated with the COVID-19 pandemic. As oil prices declined from $\sim$ USD 60 to USD 20 per barrel, emissions changed concurrently from $3.3 \%$ to $1.9 \%$ of natural gas production; as prices partially recovered, emissions increased back to near initial values. Concurrently, total oil and natural gas production only declined by $\sim 10 \%$ from the peak values seen in the months prior to the crash. Activity data indicate that a rapid decline in well development and subsequent effects on associated gas flaring and midstream infrastructure throughput are the likely drivers of temporary emission reductions. Our results, along with past satellite observations, suggest that under more typical price conditions, the Permian Basin is in a state of over-
\end{abstract}

capacity in which rapidly growing associated gas production exceeds midstream capacity and leads to high methane emissions.

\section{Introduction}

Accurate quantification of methane $\left(\mathrm{CH}_{4}\right)$ emissions from the oil and natural gas $(O \& G)$ supply chain is critical for determining the climatic impact of $O \& G$ production and use (Alvarez et al., 2012). Alvarez et al. (2018) synthesized over 400 site- and basin-level measurements to estimate United States O\&G supply chain emissions at $13 \mathrm{Tg} \mathrm{CH}_{4}$ in 2015 , equivalent to $2.3 \%$ of the nation's natural gas production and approximately $80 \%$ higher than the US Environmental Protection Agency (USEPA)'s bottom-up estimate from their 2020 US greenhouse gas inventory (USEPA, 2020a). There is growing evidence of systematic underestimation of $O \& G$ methane emissions when bottom-up methods such as emission factors and engineering equations are used rather than 
top-down atmospheric measurements, primarily due to abnormal emissions that are difficult to quantify with bottomup approaches (Allen, 2014; Brandt et al., 2014; ZavalaAraiza et al., 2017).

The Permian Basin (Fig. 1) is the most productive oil basin in the USA and rivals the Ghawar Field in Saudi Arabia for the global record (Jacobs, 2019). Although the first oil well was drilled in the Permian Basin nearly 100 years ago, the basin has experienced rapid growth in recent years as directional drilling and hydraulic fracturing allowed for production from unconventional reservoirs (Enverus, 2021). In 2019, the Permian Basin had $\sim 600$ new wells drilled per month and produced an average of 4.3 million barrels (bbl) $\left(6.8 \times 10^{8} \mathrm{~L}\right)$ of oil and 15 billion cubic feet $(\mathrm{Bcf})$ $\left(4.2 \times 10^{8} \mathrm{~m}^{3}\right)$ of natural gas per day, more than double the 2016 average values (Enverus, 2021). The Permian Basin's limited midstream infrastructure for delivering natural gas to market results in high rates of associated gas flaring relative to other US basins. In 2019, average daily flared gas volumes were $0.8 \mathrm{Bcf}\left(2.3 \times 10^{7} \mathrm{~m}^{3}\right)$, which is $5 \%$ of the basin's natural gas production (Appendix A). There is limited methane emissions data from the Permian Basin beyond two recent studies (Zhang et al., 2020; Robertson et al., 2020). Zhang et al. (2020) used satellite observations from May 2018March 2019 in an atmospheric inversion to estimate total O\&G-related emissions in the Permian Basin of $2.7 \mathrm{Tg} \mathrm{CH}_{4}$ annually or $3.7 \%$ of regional gas production. Robertson et al. (2020) found higher well pad $\mathrm{CH}_{4}$ emission rates in the Permian Basin compared to most other US basins based on over 70 site-level measurements made in 2018. Alvarez et al. (2018), which predates these studies, had assumed other US basins were representative of the Permian; updating their estimate with the Permian Basin loss rate from Zhang et al. (2020) results in a roughly $10 \%$ increase in the US supply chain estimate to $14.2 \mathrm{Tg} \mathrm{CH}_{4}$ or $2.5 \%$ of total gas production.

In January 2020, oil prices declined as the COVID-19 pandemic triggered a global slowdown in oil and natural gas consumption; in March 2020, there was a rapid price drop when the oil oversupply was exacerbated by both the Organization of the Petroleum Exporting Countries (OPEC) failing to reach a deal to cut production and global oil storage capacity reaching its limit (Reed and Krauss, 2020). Spot prices for the US oil benchmark, known as West Texas Intermediate - Cushing (WTI-Cushing), varied dramatically during this period; price per barrel was relatively stable at USD 50-60 for most of 2019, declined to USD 20 by late April 2020, briefly dropped below zero on 20 April, and then recovered to USD 40 by early July (USEIA, 2020b). Natural gas spot prices (Henry Hub) were less volatile during this period (USD 1.50-2.00 per million British Thermal Units), continuing a gradual downward trend since late 2018 (USEIA, 2020a). In the Permian Basin, oil price is a stronger driver of well development than natural gas price since many operators view oil as the primary product. Lower

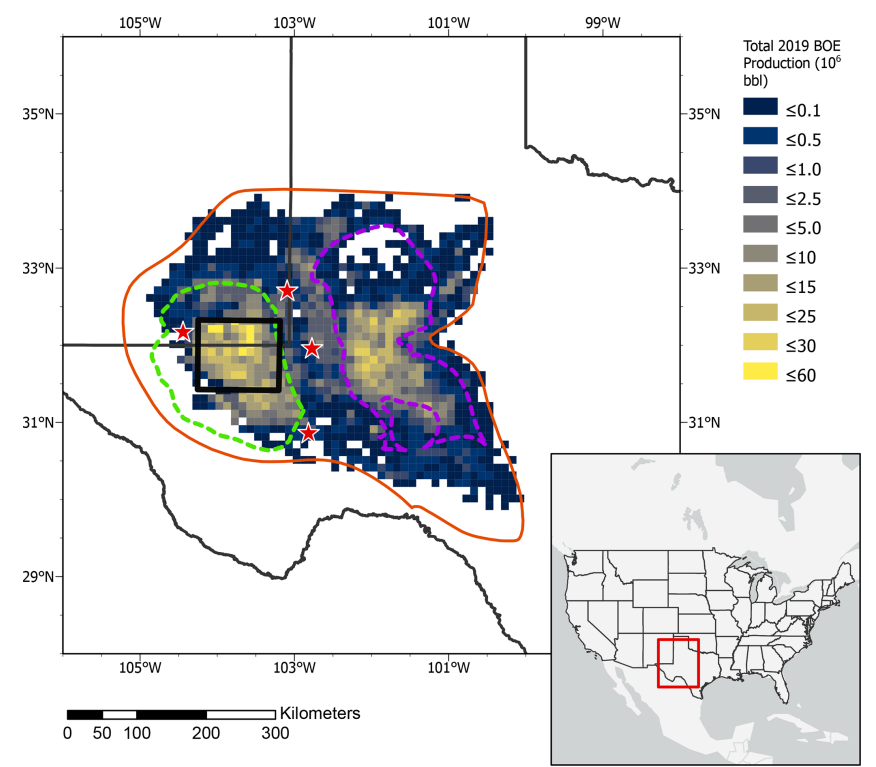

Figure 1. Regional map with outlines of the Permian Basin (orange), Delaware and Midland subbasins (dashed green and purple), and the $100 \mathrm{~km} \times 100 \mathrm{~km}$ study area (black). Locations of the methane measurement tower sites are shown with red stars. A heatmap displays combined natural gas and oil production from 2019 expressed in barrel-of-oil equivalent (BOE) and gridded to $0.1^{\circ} \times 0.1^{\circ}$ resolution (Enverus, 2021). Map was generated in ArcGIS Pro with imagery provided by Esri, Garmin, FAO, NOAA, and USGS.

commodity prices reduce investment in new well and infrastructure development; in the Permian Basin, the number of active drilling rigs, which had averaged over 400 from April 2019 to March 2020, dropped below 200 by early May and reached a minimum of 123 in September (Baker-Hughes, 2020) (Fig. 2).

We hypothesize that the rapid drop in oil price would be affiliated with a concomitant reduction in methane emissions due to lower rates of well development and a subsequent decline in oil and natural gas production. The postulated causal mechanism for this relationship is the effect of associated natural gas production from new wells on midstream infrastructure throughput. During periods of higher commodity prices, the rapid growth in natural gas production likely exceeds the capacity of the midstream pipelines, compressor stations, and processing plants that deliver natural gas to market, leading to associated gas flaring and anomalous conditions such as over-pressurization that increase emissions. Such trends were observed in an earlier drilling slowdown in the Bakken region, another US unconventional oil formation (Enverus, 2021) (Fig. F1). However, this effect might have been countered in the Permian Basin if lower profit margins led operators to allocate fewer resources to infrastructure maintenance and emissions mitigation, or similarly, restrictions due to COVID-19 reduced the number of field staff 


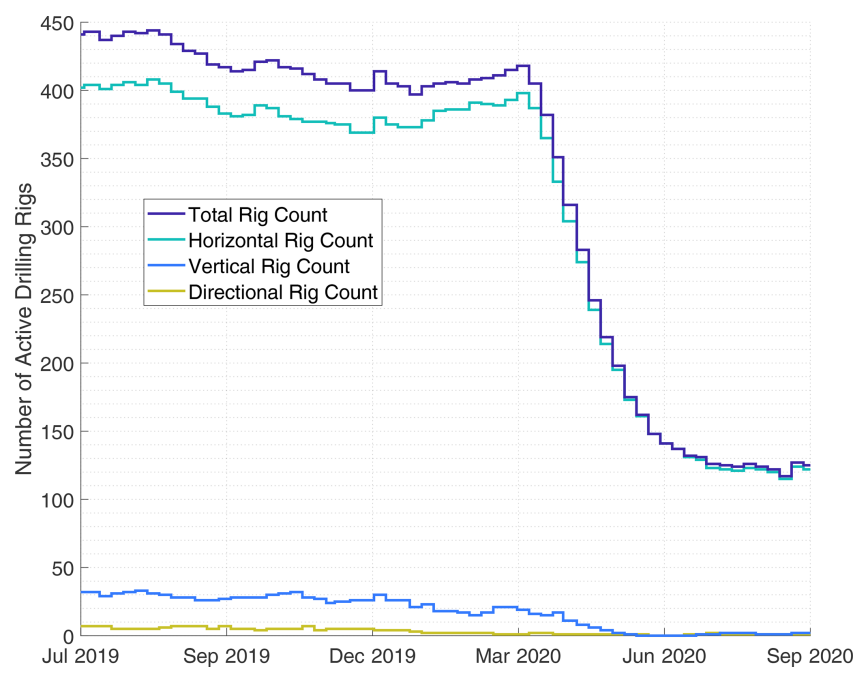

Figure 2. Weekly count of active drilling rigs by type in the Permian Basin between July 2019 and August 2020 (Baker Hughes, 2020).

performing tasks such as leak detection and repair (LDAR) (Gould et al., 2020).

\section{Study area and methods}

\subsection{Study area description}

In January 2020, we began quantifying O\&G methane emissions at varying spatiotemporal scales within the Permian Basin with a concentrated effort within a $100 \mathrm{~km} \times 100 \mathrm{~km}$ area of the Delaware subbasin along the Texas-New Mexico border (Fig. 1). The $10000 \mathrm{~km}^{2}$ study area includes $\sim 11000$ active wells and accounts for $33 \%$ and $43 \%$ of the Permian Basin's oil and natural gas production in 2019, respectively (Enverus, 2021). The study area has a high density of midstream O\&G infrastructure including at least 125 gathering and transmission compressor stations, 44 processing plants, and $\sim 32000 \mathrm{~km}$ of gathering pipeline (Enverus, 2021). Based on spatially allocated USEPA inventory data, O\&G sources accounted for $>90 \%$ of methane emissions in the study area in 2012; other sources, dominated by agriculture and waste, were responsible for $\sim 0.5 \mathrm{MgCH}_{4} \mathrm{~h}^{-1}$ (Maasakkers et al., 2016). Since the non-O\&G sources account for only a small fraction of total emissions and there have been no major changes in these activities over the past few years, we have assumed all study area emissions are attributable to O\&G sources beyond the $0.5 \mathrm{Mg} \mathrm{CH}_{4} \mathrm{~h}^{-1}$.

\subsection{Method overview}

Between January and August 2020, we used two inversion approaches to quantify total methane emission flux from the study area at a weekly to monthly frequency. The first approach used aircraft-based instruments to measure atmospheric boundary layer (ABL) methane concentration $\left(\left[\mathrm{CH}_{4}\right]\right)$ along the study area perimeter during six daytime flights (22 January, 9 March, 25 March, 4 May, 21 May, and 13 July; Sect. 2.2.2). The second approach continuously quantified $\left[\mathrm{CH}_{4}\right]$ from March through August 2020 using sensors installed at three tall towers and one mountaintop station located around the perimeter of the study area (Richardson et al., 2017; Sect. 2.2.1). Both approaches estimated study area methane flux on a daily basis by optimizing a prior emissions inventory to minimize model-data differences between observed and simulated regional atmospheric $\left[\mathrm{CH}_{4}\right]$ (Barkley et al., 2017; Sect. 2.2.1 and 2.2.3).

We also evaluated satellite-based remote sensing observations of column methane enhancement $\left(\triangle \mathrm{XCH}_{4}\right)$ for evidence of basin-wide trends (Sect. 2.2.4). To provide insights about the contribution of natural gas flares to methane emissions, we qualitatively assessed over 300 flares across the basin in February, March, and June 2020 using helicopterbased infrared optical gas imaging (OGI) to visually detect the prevalence of unlit flares and combustion issues (Lyon et al., 2016; Appendix B). We estimated flare-related methane emissions by applying combustion efficiency assumptions based on survey results to flared gas volume estimates based on satellite observations of flare radiant heat by the Visible Infrared Imaging Radiometer Suite (VIIRS) (Elvidge et al., 2016; Appendix A).

\subsubsection{Regional atmospheric $\left[\mathrm{CH}_{4}\right]$ reanalysis}

An atmospheric reanalysis similar to the system used in previous studies (Barkley et al., 2019, 2017) was used to create simulated regional atmospheric $\left[\mathrm{CH}_{4}\right]$ estimates. The modeling system used the Weather Research and Forecasting (WRF) model coupled with chemistry (WRFChem v3.6) (Skamarock et al., 2008) configured to simulate two domains, an outer $2600 \mathrm{~km} \times 2100 \mathrm{~km}$ domain with $9 \mathrm{~km} \times 9 \mathrm{~km}$ horizontal resolution and 50 vertical levels, with about 30 of these levels in the lowest $3 \mathrm{~km}$ above ground level, and an inner $830 \mathrm{~km} \times 830 \mathrm{~km}$ domain with $3 \mathrm{~km} \times 3 \mathrm{~km}$ horizontal resolution and the same vertical layers. The outer domain is nudged to ERA5 wind, temperature and water vapor reanalyses, and the inner domain is nudged to regional observations including $\sim 50 \mathrm{US} \mathrm{Na}-$ tional Weather Service and World Meteorological Organization (WMO) surface stations, five National Weather Service rawinsonde site soundings launched at 00:00 and 12:00 UTC, and the meteorological measurements from commercial aircraft. Our choice of parameterization schemes within WRFChem matches previous studies (Barkley et al., 2019, 2017).

Only atmospheric $\left[\mathrm{CH}_{4}\right]$ from emissions within the model domain are simulated, using techniques demonstrated previously (Barkley et al., 2019, 2017). Preliminary estimates of surface fluxes of $\left[\mathrm{CH}_{4}\right]$ within the domain are taken from the USEPA 2012 gridded inventory (Maasakkers et al., 2016), save for the Permian Basin where an updated, production- 
based inventory is used. This updated inventory is described in detail by Zhang et al. (2020). Briefly, production site $\mathrm{CH}_{4}$ emission factors were developed using methods in ZavalaAraiza et al. (2015) and based on measurements by Robertson et al. (2020), which accounted for complexity of well site infrastructure and their related $\mathrm{CH}_{4}$ emissions. Total basinwide $\mathrm{CH}_{4}$ emissions were estimated using activity (Enverus, 2021) and disaggregated to individual sites based on their gas production. Additional facility-level $\mathrm{CH}_{4}$ emissions for gathering and boosting stations, gathering pipelines, and processing plants were estimated based on activity data (Enverus, 2021) as well as $\mathrm{CH}_{4}$ emission factors from Marchese et al. (2015) and the USEPA GHGI (USEPA, 2020a). For the transmission and storage stations, $\mathrm{CH}_{4}$ emissions were taken from Maasakkers et al. (2016). For the Delaware subbasin, total $\mathrm{CH}_{4}$ emissions were estimated at 1.2, 0.11, 0.04, and $0.01 \mathrm{Tg}$ for production sites, gathering and boosting stations, gas processing plants, and gas transmission and distribution stations, respectively. These point-source oil and natural gas $\mathrm{CH}_{4}$ emissions were then spatially allocated to a $0.1^{\circ} \times 0.1^{\circ}$ grid over the entire basin. This update within the Delaware subbasin is important to account for the rapid development within the basin since 2012. Different $\left[\mathrm{CH}_{4}\right]$ sources (e.g., oil and natural gas production, landfills, agriculture) and sources inside and outside the study domain are tagged as independent tracers in the model. Oil and gas emissions outside of the study domain are multiplied by 1.6 to match estimates from Alvarez et al. (2018) and to better account for development in the areas surrounding the study domain. This atmospheric reanalysis system enables us to create a first estimate of atmospheric $\left[\mathrm{CH}_{4}\right]$ consistent with the regional meteorology and the preliminary estimate of sources within the outer model domain.

Note that the emissions magnitude from the preliminary $\left[\mathrm{CH}_{4}\right]$ emissions estimates is not highly important since the emissions estimate is not a Bayesian inversion that assigns an uncertainty estimate to this preliminary estimate. The spatial pattern of emissions, however, including the relative change in these spatial patterns, is important for the estimate of fluxes. Our assumption that emissions are proportional to gas production should provide a reasonable estimate of the spatial pattern of emissions corresponding to the location of oil and natural gas infrastructure (Maasakkers et al., 2016).

\subsubsection{Aircraft-based methane emission estimates}

The total $\mathrm{CH}_{4}$ emissions in the Permian Basin study area were determined using airborne data in conjunction with transport modeling. The airborne platform has been deployed and described previously (Conley et al., 2017, 2016; Karion et al., 2015; Smith et al., 2017). In brief, a singleengine Mooney aircraft is outfitted with a Picarro cavity ringdown spectrometer (CRDS) instrument (G2210-m) to measure in situ atmospheric $\mathrm{CH}_{4}, \mathrm{CO}_{2}$, and $\mathrm{H}_{2} \mathrm{O}$ mole fractions; a differential GPS and aircraft data computer to enable computation of horizontal wind speeds and directions; and a Vaisala probe to measure ambient temperature and relative humidity (RH).

On each flight day, two laps consisting of a box enclosing the $100 \mathrm{~km} \times 100 \mathrm{~km}$ study area were flown at $335 \pm 30 \mathrm{~m}$ above ground level (a.g.l.), with one complete lap taking $\sim 2 \mathrm{~h}$ to complete. Two to three vertical profiles were also flown by the aircraft as pairs of ascents and descents between the lowest safe flight altitude (typically 61 to $152 \mathrm{~m}$ a.g.l.) and the flight altitude at which significant changes are observed in measured species concentrations (e.g., $\mathrm{CH}_{4}$, water vapor, relative humidity, and potential temperature) - typically 914 to $3048 \mathrm{~m}$ a.g.l. Plots of a.g.l. altitude versus these species are used to assess the mixing height of surface emissions. Both $\mathrm{CH}_{4}$ concentrations along the flight path and the mixing height determined from the airborne vertical profiles are used in transport modeling to determine emissions from the entire study area.

$\left[\mathrm{CH}_{4}\right]$ emissions are computed from each complete circuit of the study area by the aircraft. This is done by comparing the observed and simulated $\left[\mathrm{CH}_{4}\right]$ enhancement, the increase in $\left[\mathrm{CH}_{4}\right]$ downwind of the study area relative to a background value, and adjusting emissions within the study area to minimize the absolute error between the simulated and observed atmospheric boundary layer $\left[\mathrm{CH}_{4}\right]$. The 10th percentile of $\left[\mathrm{CH}_{4}\right]$ observations in the circuit determines the background. This mole fraction value is subtracted from the observed $\left[\mathrm{CH}_{4}\right]$ observations, resulting in an estimate of $\left[\mathrm{CH}_{4}\right]$ enhancements. These observed enhancements are then compared to simulated $\left[\mathrm{CH}_{4}\right]$ enhancements by matching observation and model at the nearest grid points in space and time. Simulated enhancements are split into two categories: study domain enhancements and enhancements originating from outside the study domain. Enhancements associated with sources outside the study domain are subtracted from the observed $\left[\mathrm{CH}_{4}\right]$ enhancements, resulting in a set of observations whose enhancements can be directly attributed to emissions within the study domain. The simulated study domain enhancements are then compared to the observed study domain enhancement, and a scalar multiplier is applied to the simulated enhancements to minimize the absolute error between the two datasets. Because the emissions scale linearly with the simulated enhancements, this scalar multiplier, applied to the preliminary emissions estimate within the study area, provides a solution to the emissions within the study domain (Barkley et al., 2017). The solution for each circuit is merged into a single daily estimate.

To test the uncertainty of the emission rate solution for each flight day, a 1000-iteration Monte Carlo uncertainty assessment was performed, adjusting various parameters to test how they impacted the solution. Through the iterations, we examine the impact of various possible sources of error, including uncertainty in the background, uncertainty in the assumed influence from sources outside the domain, and uncertainty in the atmospheric transport. For uncertainty in the 


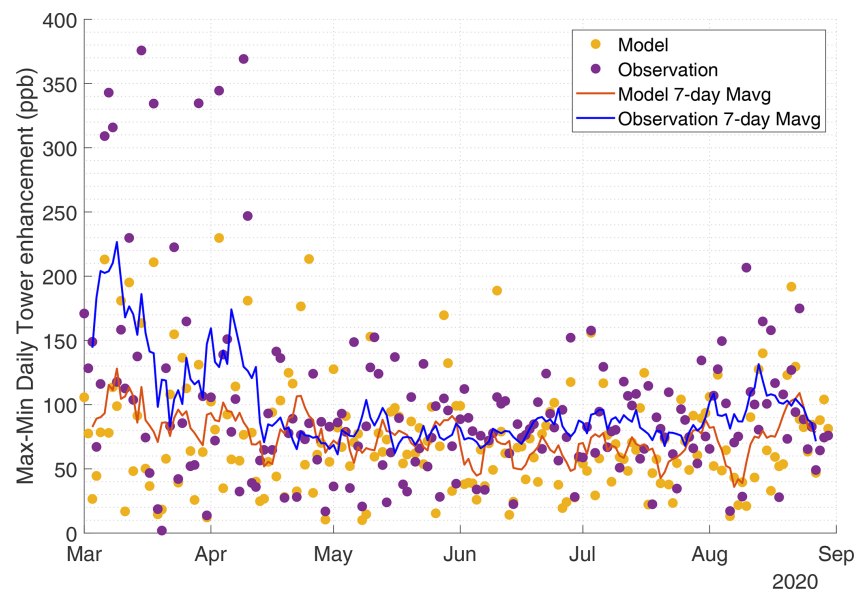

Figure 3. Comparison between modeled and observed differences in the maximum and minimum daily $\mathrm{CH}_{4}$ enhancement across the tower network. Also shown are the $7 \mathrm{~d}$ moving averages (Mavg) of each trend.

background, we select a random percentile between the 5th and 15 th to use as the methane background in a flight lap. For uncertainty in sources outside of the domain that are subtracted from the observations, we multiply the "other" enhancement tracer by a random factor between 0.5 and 1.5 to account for the possibility that regional emissions may be incorrect. For uncertainty in the transport, the time of the observations is adjusted by $\pm 30 \mathrm{~min}$, creating perturbations to the model output timeframe used to compare to the observations. From the 1000 iterations, the 2.5 th and 97.5 th percentiles of solutions are chosen to represent the $95 \%$ confidence interval.

\subsubsection{Tower-based methane emissions estimates}

Atmospheric mole fraction measurements of $\mathrm{CH}_{4}$ and $\mathrm{CO}_{2}$ were collected at five locations in the Permian Basin beginning 1 March 2020, using methods similar to those described in Richardson et al. (2017). A map of the measurement locations, along with oil and gas facilities in the Permian Basin, is shown in Fig. 1. Note that only four of the five planned measurement sites are used in this analysis and shown in Fig. 1 due to instrument malfunctions at the northernmost site. Of these measurement locations, three were on towers at measurement heights of 91-134 ma.g.l., and the westernmost site was at a mountaintop station on a rooftop $4 \mathrm{~m}$ a.g.l. The measurements were made with wavelength-scanned cavity ring-down spectroscopic instruments (Picarro, Inc., models G2301, G2401, G2204, and G2132-i). The air samples were dried using Nafion dryers (Perma Pure, Inc.) in reflux mode, with an internal water vapor correction applied for the effects of the remaining water vapor $(<1 \%)$. The instruments were calibrated in the laboratory prior to deployment and using quasi-daily field tanks traceable to the WMO X2004A scale (Dlugokencky et al., 2005; NOAA, 2015). The $\mathrm{CH}_{4}$ measure- ment uncertainty values (including instrument noise, uncertainty due to water vapor calibration, and tank assignment uncertainty) for the four tower locations were $0.6 \mathrm{ppb}$ (Carlsbad), $0.6 \mathrm{ppb}$ (Fort Stockton), $3.4 \mathrm{ppb}$ (Hobbs), and $5.4 \mathrm{ppb}$ (Notrees), with the differences being attributable to different instrument types: short Nafion dryer in the case of Hobbs and laser aging for Notrees.

$\mathrm{CH}_{4}$ emissions in the study domain were calculated for each day of tower observations using a similar technique as used with the aircraft observations. Daily afternoon $\left[\mathrm{CH}_{4}\right]$ at each tower site averaged from 16:00-22:00 UTC (11:0017:00 local standard time) was computed from both the observations and the simulation. A background $\left[\mathrm{CH}_{4}\right]$ value (both for the observations and the model) is selected based on the lowest measurement from the available tower sites. This background is subtracted from all tower sites to create an observed $\left[\mathrm{CH}_{4}\right]$ enhancement. Simulated enhancements from sources outside of the domain are subtracted from the observed enhancements to produce an observed $\left[\mathrm{CH}_{4}\right]$ enhancement associated with sources inside the study domain. A scalar multiplier is then applied to minimize the absolute error between the observed and modeled enhancements, and a daily emission rate is solved for in the study domain.

Unlike the aircraft mass balance observations, which are collected on days when meteorological conditions are ideal for measuring emissions from the study domain, the tower dataset is continuous, and many days may not be suitable for calculating an emission rate from the study domain. The most useful tower observations for solving for emissions within the study domain are those whose enhancements are influenced primarily by sources within the study domain and contain minimal enhancements from sources outside of the domain. We select for these conditions by retaining days when $>50 \%$ of the simulated downwind afternoon tower enhancements come from sources within the study domain. This filtering removes 85 of 184 available days, most of which have easterly winds and contain air masses heavily influenced by the Midland subbasin to the east as well as oil and gas basins in central and eastern Texas. For the remaining $99 \mathrm{~d}$, we remove $4 \mathrm{~d}$ whose solutions are more than 3 median absolute deviations away from the median solution, presumably caused by issues in the model transport; excluding these outlier days has a minor impact on overall results. In total, $95 \mathrm{~d}$ is used to calculate emissions and trends in the tower dataset between 1 March and 30 August 2020.

\subsubsection{TROPOMI-derived column-averaged methane mixing ratios}

We use column-averaged dry-air methane mixing ratios $\left(\mathrm{XCH}_{4}\right)$ from the TROPOspheric Monitoring Instrument (TROPOMI) from January to June 2020. TROPOMI was launched in October 2017 aboard the polar sun-synchronous Sentinel-5 Precursor satellite with an $\sim 13: 30$ local overpass time. It provides daily global coverage with $7 \mathrm{~km} \times 7 \mathrm{~km}$ 


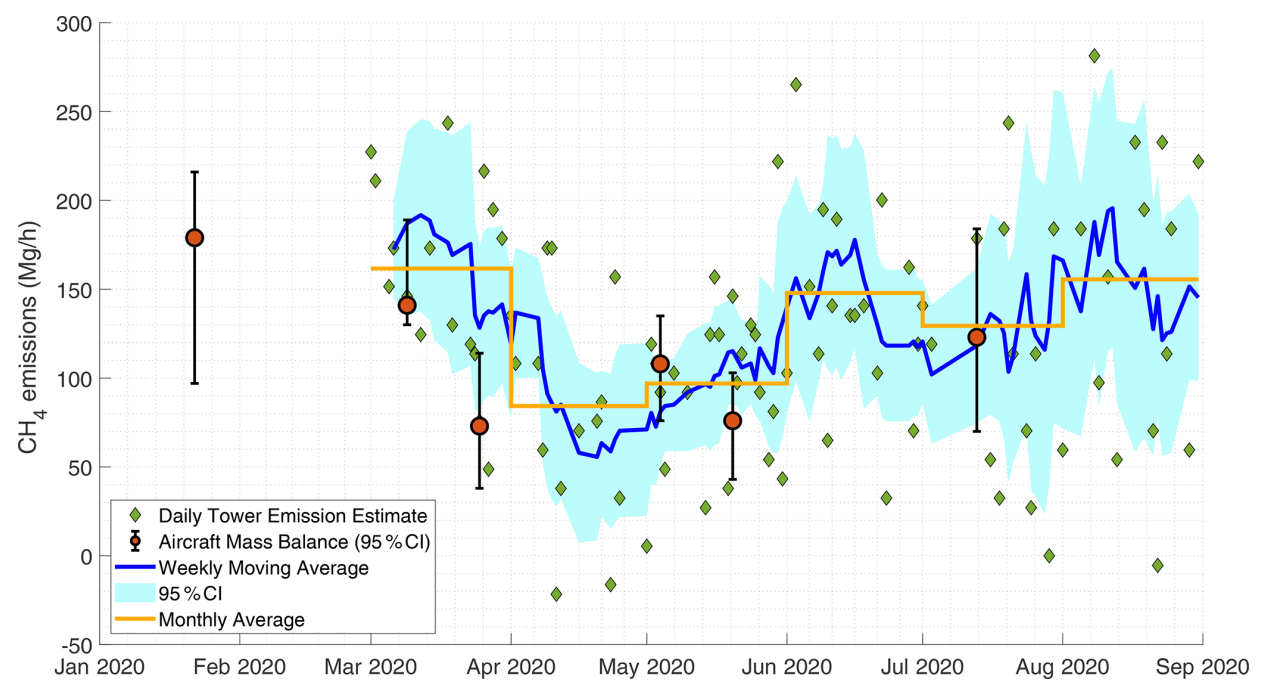

Figure 4. Tower and aerial emission estimates from the $100 \mathrm{~km} \times 100 \mathrm{~km}$ study area through 31 August 2020. Individual daily accepted estimates from the tower observations are shown in green diamonds, while red circles with error bars represent the aerial estimate and $95 \%$ CI (confidence interval) range. The blue line represents the 7-data-point moving average of the tower estimates and the light blue shading shows the $95 \% \mathrm{CI}$ range expressed as twice the 7-data-point moving standard error. The orange line represents the monthly average estimate from the combination of aerial and tower-based methods which weights tower and aircraft-based estimates equally.

Table 1. Numerical estimates of $\mathrm{CH}_{4}$ flux from the $100 \mathrm{~km} \times 100 \mathrm{~km}$ study area derived from the combination of tower and aerial measurements across several temporal ranges.

\begin{tabular}{|c|c|c|c|c|c|}
\hline Time range & $\begin{array}{r}\text { Mean emissions } \\
\qquad\left(\mathrm{Mg} \mathrm{h}^{-1}\right)\end{array}$ & $\begin{array}{l}\text { Number of accepted daily } \\
\text { measurements (tower, aircraft) }\end{array}$ & $\begin{array}{r}\text { Standard deviation } \\
\left(\mathrm{Mg} \mathrm{h}^{-1}\right)\end{array}$ & $\begin{array}{r}\text { Standard error } \\
\left(\mathrm{Mg} \mathrm{h}^{-1}\right)\end{array}$ & $\begin{array}{r}95 \% \mathrm{CI} \\
\text { emission estimate }\end{array}$ \\
\hline Mar 2020 & 162 & $(17,2)$ & 67 & 15 & $131-193$ \\
\hline Apr 2020 & 84 & $(14,0)$ & 63 & 17 & $50-118$ \\
\hline May 2020 & 97 & $(22,2)$ & 47 & 10 & $78-116$ \\
\hline Jun 2020 & 148 & $(18,0)$ & 73 & 17 & $113-182$ \\
\hline Jul 2020 & 129 & $(14,1)$ & 93 & 24 & $82-177$ \\
\hline Aug 2020 & 156 & $(16,0)$ & 97 & 24 & $107-204$ \\
\hline "Pre-Crash Period" 22 Jan-19 Mar 2020 & 186 & $(10,2)$ & 59 & 17 & $152-220$ \\
\hline "Emissions Minima" 11 Apr-5 May 2020 & 65 & $(13,1)$ & 53 & 14 & $36-93$ \\
\hline
\end{tabular}

pixel resolution at nadir (Hu et al., 2018); the pixel resolution has changed to $\sim 7 \mathrm{~km} \times 5.5 \mathrm{~km}$ at nadir since August 2019. The $\mathrm{XCH}_{4}$ retrieval uses sunlight backscattered by the Earth's surface and atmosphere in the shortwave infrared (SWIR) spectral range and has near-unit sensitivity down to the surface (Hasekamp et al., 2019). Here we consider only higher-quality $\mathrm{XCH}_{4}$ measurements based on published quality assurance metrics (quality assurance value $>0.5$; Apituley et al., 2017).

We calculate the daily methane enhancements over the Permian Basin from topography-corrected $\mathrm{XCH}_{4}$, relative to a regional background column defined by the 10th percentile of $\mathrm{XCH}_{4}$ across the full Permian Basin domain $\left(29-34^{\circ} \mathrm{N}\right.$ and $100-106^{\circ} \mathrm{W}$ ). The topography correction is based on a linear regression of $\mathrm{XCH}_{4}$ against surface altitude (similar to the methodology presented in Kort et al., 2014, and Zhang et al., 2020, performed across the continental United States $\left(25-48^{\circ} \mathrm{N}\right.$ and $\left.66-125^{\circ} \mathrm{W}\right)$ ). Roughly $5000-14000$
TROPOMI observations are available per month across this domain, neglecting March and June (Fig. 5c). To mitigate the impact of reduced spatial coverage on our change analysis after February, we manually discard observations from days with little to no coverage of the Delaware and/or Midland subbasins. Data from $20 \%-40 \%$ of observation days in January, February, April, and May (depending on the month) are discarded in this way, but the total number of observations is reduced by only $5 \%$.

Repeating our analysis with the background defined at the 25th percentile level (rather than the 10th), we find that trends are insensitive to the percentile value used. Furthermore, the trends are not explained by seasonal changes in wind speed across the Permian Basin. Higher winds could lead to lower enhancements, but data from the NASA GEOS-FP (Lucchesi, 2013) meteorological reanalysis product indicate that the daily wind speed averaged over the full Permian Basin domain, in the lowest $3 \mathrm{~km}$ of the atmosphere, during the $6 \mathrm{~h}$ 

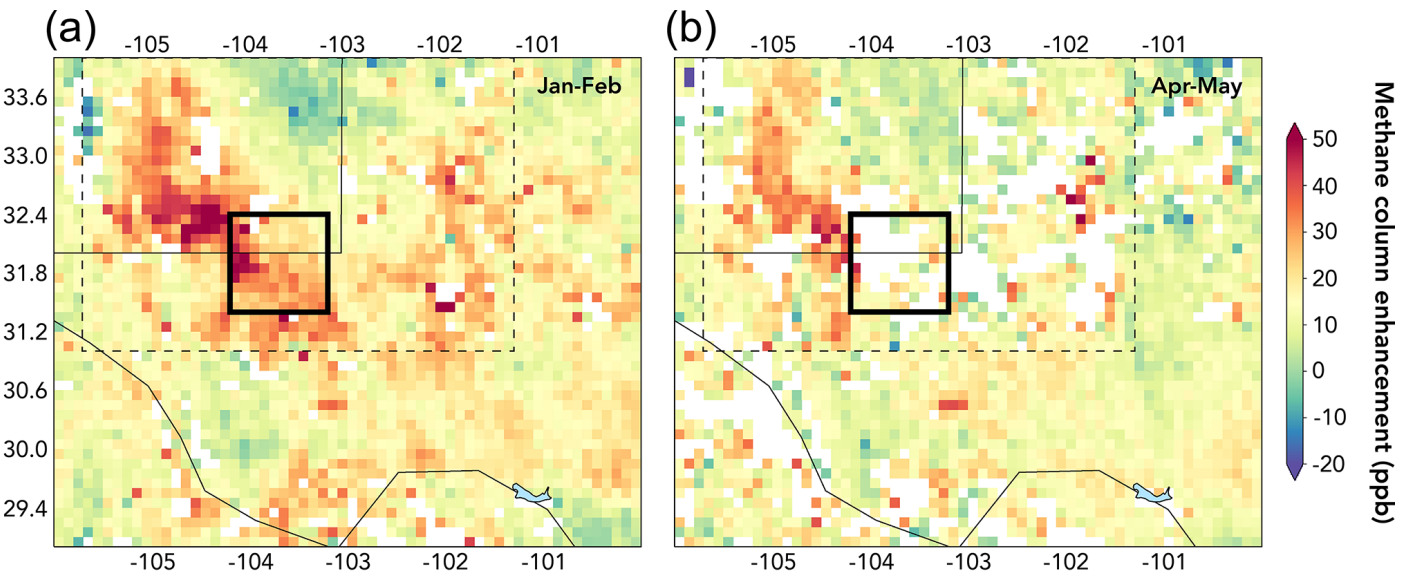

(c)

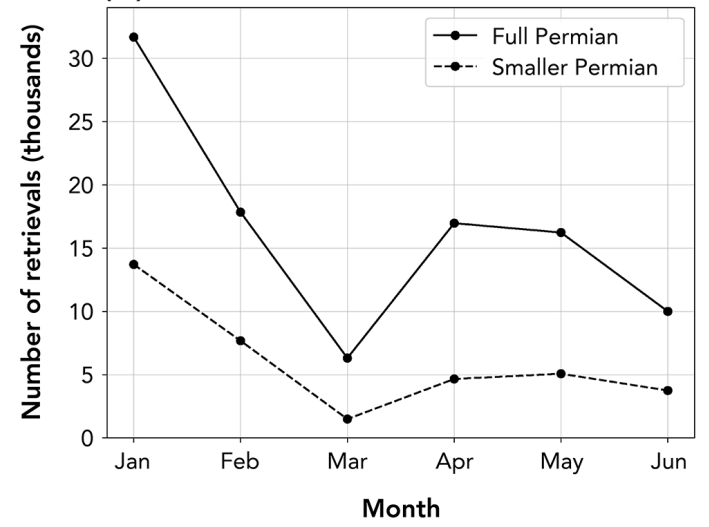

(d)

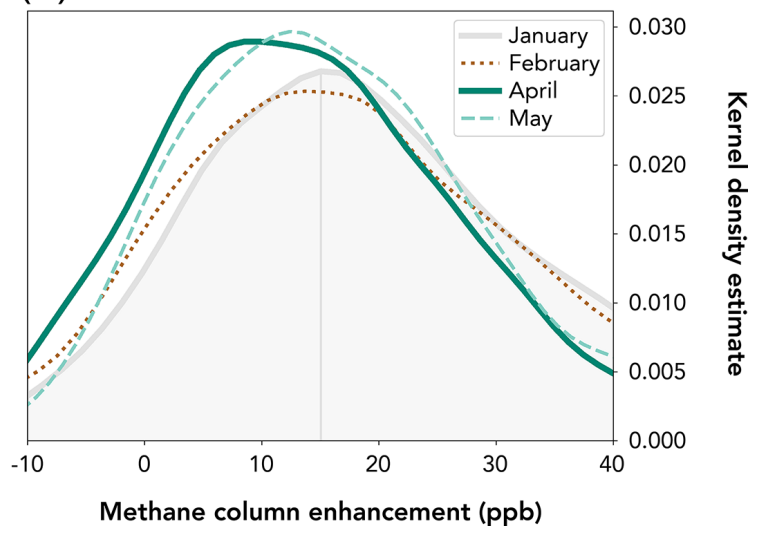

Figure 5. TROPOMI observations of topography-corrected methane column enhancements over the Permian Basin, from January to June 2020. (a-b) Mean methane column enhancements (ppb) over the Permian Basin for the January-February and April-May 2020 time periods, gridded to $0.1^{\circ} \times 0.1^{\circ}$ resolution. The thin solid lines indicate state and national borders; the thick solid lines describe the $100 \mathrm{~km} \times 100 \mathrm{~km}$ tower and aircraft study region; and the dotted lines trace a smaller Permian Basin domain that closely bounds the methane hotspots seen over the Delaware and Midland subbasins. (c) Number of TROPOMI column retrievals over the full Permian Basin domain $\left(29-34^{\circ} \mathrm{N}\right.$ and $\left.100-106^{\circ} \mathrm{W}\right)$ and over the smaller Permian Basin domain (31-34 ${ }^{\circ} \mathrm{N}$ and $101.4-105.6^{\circ} \mathrm{W}$; dashed lines in panels a, b) by month in 2020. (d) Frequency distribution plots of methane column enhancements over the smaller Permian Basin domain by month, after removal of days without coverage of the Delaware and/or Midland subbasins (see text). The gray vertical line indicates the distribution maximum for January.

closest to TROPOMI observation time (15:00-21:00 UTC), decreased from a mean of $7.02 \mathrm{~m} \mathrm{~s}^{-1}$ in January-February to $5.48 \mathrm{~m} \mathrm{~s}^{-1}$ in April-May.

\section{Results}

\subsection{Tower and aircraft-based methane emissions estimates}

Figure 3 presents the daily difference between the highest and lowest observed $\mathrm{CH}_{4}$ measurement across the tower network. Although the overall magnitude of the study area plume observed at the tower network can be affected by various meteorological factors (e.g., wind speed, direction, boundary layer height), large changes in the typical size of the observed plumes can be indicative of a sudden shift in behavior of local emissions. From the tower network, we frequently observe large enhancements $>200 \mathrm{ppb}$ in March and mid-April, after which point the enhancement rarely increases above $150 \mathrm{ppb}$ for the remainder of the summer months. It should be noted that a slight decrease in the size of the enhancements would be expected during this period due to increased vertical mixing in a seasonally growing boundary layer; however, modeled results from this time span exhibit a much smaller magnitude of change. Therefore, the dramatic decline in $\mathrm{CH}_{4}$ enhancements coincident with the timing of the price crash is likely due to a change in the emissions rather than a change in the meteorology.

Figure 4 presents a time series of $\mathrm{CH}_{4}$ emissions within the $100 \mathrm{~km} \times 100 \mathrm{~km}$ study area between 1 March and 31 August 2020 from both aircraft and tower-based approaches. The $95 \% \mathrm{CI}$ (confidence interval) ranges are de- 


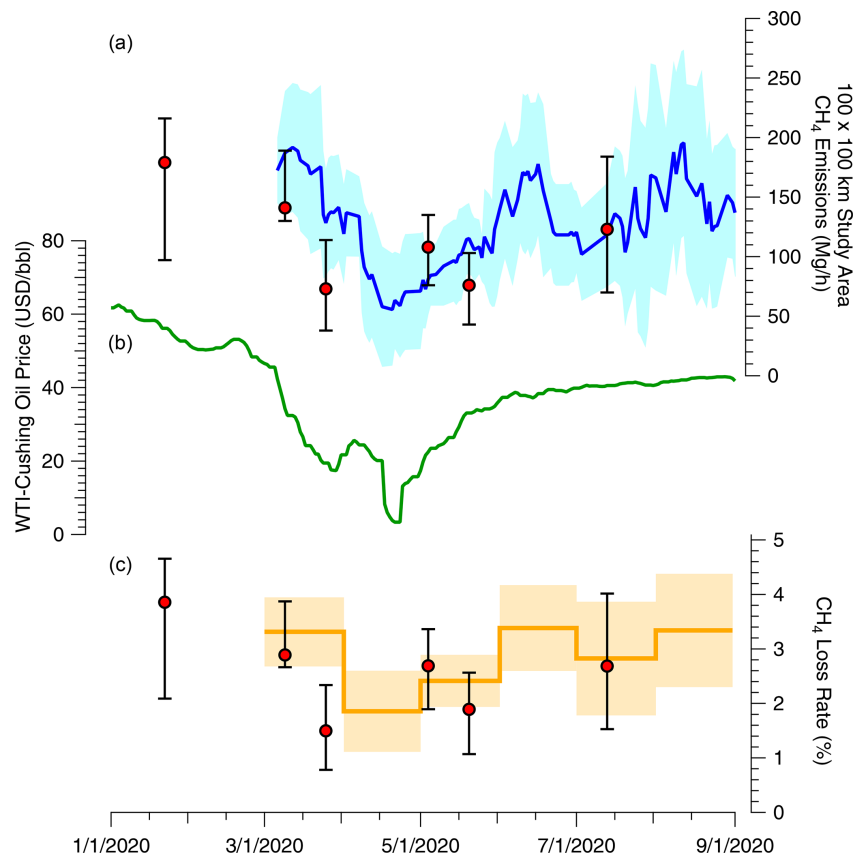

Figure 6. Temporal variation in methane emissions and crude oil price. (a) Aerial (red circles with $95 \% \mathrm{CI}$ error range) and towerbased 7-point moving average and $95 \%$ CI (blue line and shading) atmospheric estimates of $100 \mathrm{~km} \times 100 \mathrm{~km}$ study area $\mathrm{CH}_{4}$ emissions. (b) $7 \mathrm{~d}$ moving average of WTI-Cushing daily oil price. (c) Orange line and shading presents resulting $\mathrm{CH}_{4}$ loss rate combined aerial and tower-based measurements utilizing published monthly gas production within the study area (Enverus, 2021). Red points present the loss rate utilizing only the aircraft-based emission estimates and the monthly gas production during the month of the flight.

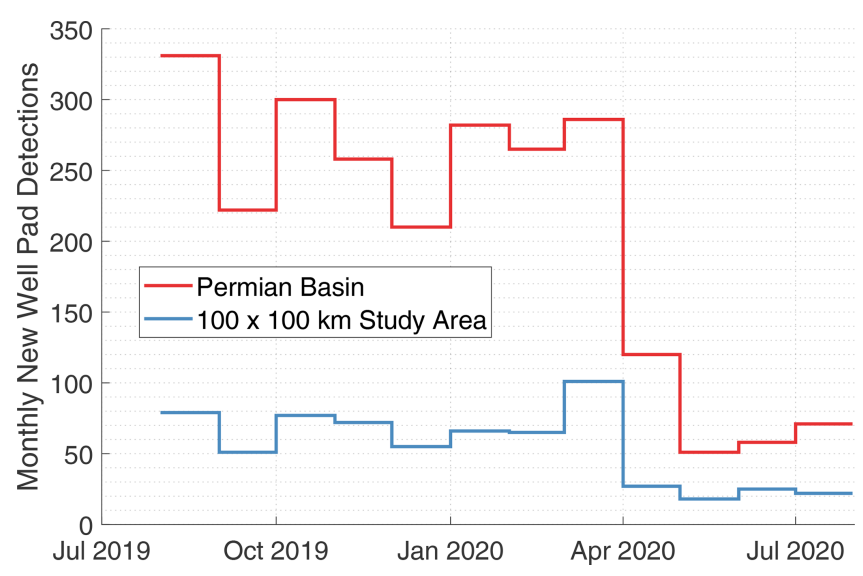

Figure 7. Number of new well pads constructed per month between 1 August 2019 and 31 July 2020 in the full Permian Basin and our $10000 \mathrm{~km}^{2}$ Delaware subbasin study area based on satellite imagery and machine learning (Appendix C). (a)

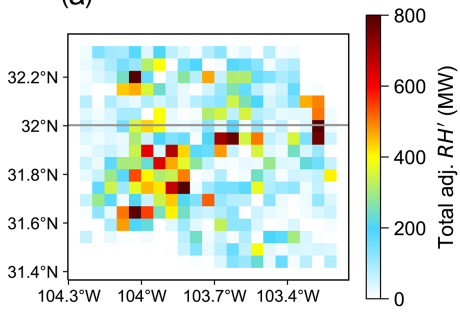

(c)

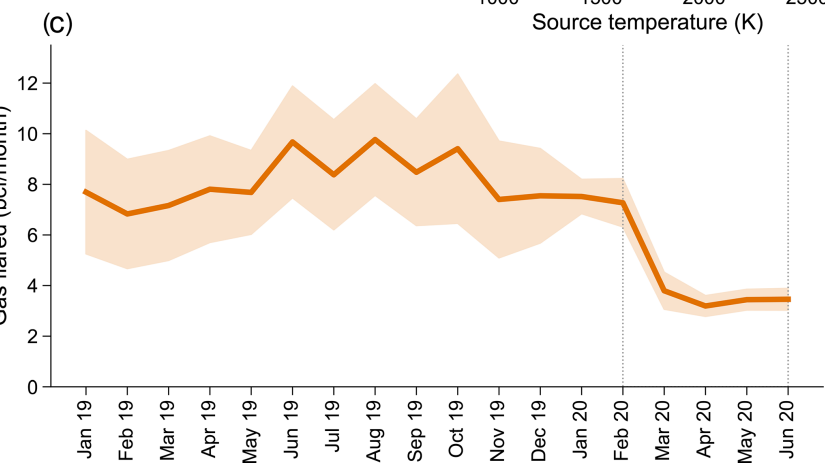

Figure 8. VIIRS-derived gas flaring in the study region. (a) Spatial distribution of the cumulative adjusted radiant heat over the period between January 2019 and June 2020 aggregated over a $0.05^{\circ} \times 0.05^{\circ}$ grid resolution. (b) Histogram of VIIRS-derived source temperatures. Dotted lines show the temperature regime characteristic of gas flaring sources $(1400-2500 \mathrm{~K})$. (c) Monthly trend in VIIRS-derived gas flared volumes. The mean estimate is shown with a solid line, and the $95 \% \mathrm{CI}$ on the mean is shown in the shaded area. 1 billion cubic feet $(\mathrm{Bcf})=2.8 \times 10^{7} \mathrm{~m}^{3}$

rived from twice the standard error of all accepted daily tower-based estimates in each month. Both aircraft and tower-based methane flux data show consistent trends of declining then rebounding methane emissions in our Permian Basin study area. Between 22 January and 19 March 2020, emissions were $186 \mathrm{MgCH}_{4} \mathrm{~h}^{-1}$ (95\% confidence interval range: $152-220 \mathrm{MgCH}_{4} \mathrm{~h}^{-1}$ ). Following the rapid decrease in oil price, emissions between 11 April and 5 May 2020 reached a minimum of $65 \mathrm{MgCH}_{4} \mathrm{~h}^{-1}(95 \% \mathrm{CI}$ range: $36-93 \mathrm{Mg} \mathrm{CH}_{4} \mathrm{~h}^{-1}$ ). After the oil price partially recovered, emissions for the month of June had increased to $148 \mathrm{MgCH}_{4} \mathrm{~h}^{-1}$ (95\% CI range $113-182 \mathrm{MgCH}_{4} \mathrm{~h}^{-1}$ ). Mean emission estimates for the remainder of the summer months were slightly below those before the crash, although show much higher uncertainty due to increased difficulty in resolving the signal of emissions from within and outside of the study area boundary due to increasing mixing depths and thus a dilution of the signal.

Combining the monthly tower and aircraft-based estimates with reported gas production (Enverus, 2021), we calculate a March 2020 loss rate of $3.3 \%$ of total gas production (95\% CI range: $2.7 \%-4.0 \%$ ), which is slightly lower but within the uncertainty of previously reported basin-wide estimates 
from 2018-2019 $(3.7 \pm 0.7(1 \sigma) \%)$ (Zhang et al., 2020). The minimum loss rate calculated for April 2020 was $1.9 \%$ of gas production (95\% CI range: $1.1 \%-2.6 \%$ ), increasing gradually for the summer months to again exceed $3.0 \%$.

\subsection{TROPOMI-derived column-averaged methane mixing ratios}

In the full Permian Basin, orbital observations of $\mathrm{XCH}_{4}$ indicate lower methane column enhancements in April-May versus January-February 2020, consistent with the aircraft and tower-based flux data (Fig. 5). Figure 5a and b show mean methane column enhancements over the Permian Basin, observed by TROPOMI in (a) January-February 2020 and (b) April-May 2020. Enhancements over the Permian Basin appear to be lower in April-May compared to JanuaryFebruary, as indicated by an $\sim 18 \%$ reduction in the regional mean between those two periods. This reduction may be due in part to lower spatial coverage after February 2020, likely caused by the introduction in March of a different cloud mask product in the TROPOMI retrieval algorithm (Siddans, 2020). Considering TROPOMI retrievals with quality assurance values of 0.5 or greater, we obtain roughly 6000-32 000 enhancement measurements per month from January to June 2020 over the full Permian Basin (Fig. 5c). The limited number of satellite observations over our $100 \mathrm{~km} \times 100 \mathrm{~km}$ study area for tower and aircraft measurements (Fig. 3) precludes direct comparison with the suborbital measurements; therefore, we provide here an analysis of TROPOMI methane enhancement over the broader Permian Basin. Coverage is particularly sparse in March and June, so we neglect those 2 months in the TROPOMI analysis presented here.

Figure 5d shows frequency distributions of methane column enhancements observed by TROPOMI in January, February, April, and May 2020. For these monthly curves, we restrict our attention to a smaller Permian Basin domain that closely bounds the methane hotspots seen over the Delaware and Midland subbasins (dashed lines in Fig. 5a, b; 31-34 ${ }^{\circ} \mathrm{N}$ and 101.4-105.6 W). Permian Basin methane enhancements as observed by TROPOMI appear to decrease in early 2020 , reaching a minimum in April before beginning to rise again in May. The trends we identify in TROPOMI methane enhancement analysis across the Permian Basin are broadly consistent with our findings from tower and aircraft observations of reduced emissions particularly during April in our campaign domain of the Delaware subbasin, but large uncertainties remain due to the different spatial domains and the reduced satellite coverage after February 2020. More data and/or more advanced analysis using inverse modeling techniques may be needed to reliably characterize Permian Basin methane emission trends using TROPOMI satellite observations.

\subsection{Emission contribution from flaring and well completions}

Well pad development in the study area proceeded at an average rate of 71 new sites per month between August 2019 and March 2020 and then dropped to a monthly average of 24 sites between April and July 2020 (Appendix C, Fig. 7). The number of well completions per month declined from 188 to 115 between January and April 2020 (Enverus, 2021); completion counts are higher than well pad development rates due to multiple wells being located on a single pad. After rising steadily throughout 2019 , oil and gas production peaked in March 2020 and then declined $9 \%$ and $8 \%$, respectively, in April. Based on adjusted, incomplete production data for May and June, gas production stayed relatively steady after April, while oil production dropped an additional 3\% (Appendix E). The relative decline in oil and natural gas production between March and April 2020 was much greater among wells in the first 2 months of production, decreasing $50 \%$ and $45 \%$, for oil and gas, respectively (Appendix E).

The three flare surveys between February and June 2020 consistently found that $11 \%$ of flares had combustion issues, with $5 \%$ unlit and emitting hydrocarbons. Even when using conservative assumptions of higher combustion efficiency, we estimate a basin-wide flare combustion efficiency of $93 \%$, with the remaining gas (assuming $80 \%$ methane content) being emitted to the atmosphere (Appendix B). Satellite observations of radiant heat indicate that flared gas volumes were cut in half from 7.6 to $3.2 \mathrm{Bcf}\left(2.2 \times 10^{8}\right.$ to $9.1 \times 10^{7} \mathrm{~m}^{3}$ ) between January and April 2020 (Fig. 8).

\section{Discussion}

The pandemic-associated oil price crash provided an unexpected opportunity to assess temporal variability in methane emissions during a period of volatile oil prices and associated operational changes. In support of our hypothesis that methane emissions would decline with oil price, we observed a threefold reduction in Permian Basin study area methane emissions that was strongly correlated to the average daily oil price. Between Q1 and Q2 2020, Permian Basin oil and natural gas production dropped about $12 \%$ and $8 \%$ respectively; the magnitude of change for oil and gas production was similarly about $11 \%$ and $9 \%$ within the $100 \mathrm{~km} \times 100 \mathrm{~km}$ study area (Fig. E1). Accordingly, the loss rate temporarily decreased from $3.3 \%$ to $1.9 \%$ of gas production between 22 January-19 March and 11 April-5 May 2020 (Appendix E). It is important to note that even the minimum observed loss rate of $1.9 \%$ is several times higher than the performance targets committed to by major oil and natural gas production companies accounting for about one-third of global oil production, including some with operations in the Permian Basin (OGCI, 2020). We hypothesize that total methane emissions are positively correlated with oil price 
due to three interrelated factors associated with well development: (1) well completion rates, (2) associated gas flaring volumes, and (3) indirect impacts of new associated gas production on the gathering and processing system.

Lower oil prices directly led to reduced emissions by decreasing well development activities, as we observed for rig count, new site construction, and well completions following the price crash. Well development activities are an intermittent source of methane emissions, particularly completion flowback, the typically multiday period following hydraulic fracturing when fluids, excess proppant, and entrained gas are expelled from the wellbore (Allen et al., 2013). We estimate that the $\sim 70$ fewer well completions in April versus January 2020 caused average potential flowback emissions in our study area to decline from 45 to $26 \mathrm{Mg} \mathrm{CH}_{4} \mathrm{~h}^{-1}$ (Appendix D). At the time of the study, US federal regulations mandated the use of reduced emission completions to control emissions in most situations; operator reported data suggest actual emissions $\left(2-4 \mathrm{MgCH}_{4} \mathrm{~h}^{-1}\right)$ are less than $10 \%$ of potential emissions (USEPA, 2019, 2020b; Appendix D).

The observed twofold reduction in flared gas volumes between January and April 2020 was likely the result of the large drop in associated gas production from new wells. Unconventional wells tend to have high initial gas production followed by steep declines. With lower rates of well development and new gas production in the area, competition for limited gas pipeline capacity likely was abated, leading to less flaring of stranded associated gas. Assuming a combustion efficiency of $93 \%$, we estimate flare-related methane emissions in our study area were approximately 8 and $3 \mathrm{MgCH}_{4} \mathrm{~h}^{-1}$ in January and April 2020, respectively (Appendix A). Our combustion efficiency assumption, which is based on repeat observations of over 300 flares, is conservatively high; therefore, our emission estimate represents a lower bound. However, even with worst-case assumptions of flare combustion efficiency, it is unlikely that January and April flare-related emissions would have exceeded 20 and $7 \mathrm{MgCH}_{4} \mathrm{~h}^{-1}$, respectively (Appendix B).

Our estimates of well completion and flare-related methane emissions account for less than $20 \%$ of the observed total reduction between pre-crash and minimum price conditions; therefore, we theorize that the primary driver of emission reductions is indirect improvements to the performance of the midstream gathering and processing system resulting from reduced inputs of gas from new wells. This result suggests that the high methane emission rate observed in the Permian Basin in recent years is in large part due to insufficient capacity of midstream infrastructure for handling and delivering rapidly growing rates of natural gas production (Zhang et al., 2020). The drastic decline in flared associated gas volumes during the oil price crash suggests that the reduction in new gas production relieved midstream capacity issues. A similar pattern was observed in the Bakken formation during the oil price decline of 2015-2016: price drops caused only a small decrease in total production but a large decrease in drilling and flaring rates (Appendix F). Our study provides the first direct evidence of reduced methane emissions resulting from an apparent abatement of infrastructure capacity limitations.

The high methane emission rate observed in the Permian Basin during periods of higher oil commodity prices is likely a consequence of associated gas production increasing at a faster rate than midstream infrastructure capacity for sending gas downstream. This leads to both intentional flaring of stranded gas and fugitive emissions from anomalous conditions related to excess gas throughput (e.g., pressure relief venting). Our observations of emissions declining concurrently with new well development suggest that methane emissions could be mitigated in the Permian Basin and similar oil-producing fields by better aligning development rates of wells and midstream infrastructure. For example, regulations could prohibit the drilling of wells in areas without sufficient capacity to transport newly produced associated gas to market. Our findings suggest that policies which tie the maximum rate of well development to infrastructure capacity, in addition to other approaches such as requiring highfrequency or continuous monitoring to detect large emission sources (Alvarez et al., 2018), can facilitate lower methane emissions that reduce the climatic impact of oil and gas production. 


\section{Appendix A: VIIRS-derived flared natural gas volumes}

We assess the monthly trends in the volumes of natural gas flared in the study region using nighttime fire and flare data observed by the Visible Infrared Imaging Radiometer Suite (VIIRS) instrument aboard the Suomi National Polarorbiting Partnership satellite. Specifically, we use the VIIRS NightFire V3.0 data product to support our analysis (Elvidge et al., 2013) For the study region and for the period between January 2019 and June 2020, we retrieved 49885 individual VIIRS detections for which it was possible to estimate flaring source temperatures based on Planck curve fitting of the source radiances (Elvidge et al., 2013). During this period, the mean VIIRS-derived source temperature was $1869 \mathrm{~K}$. The histogram of source temperatures is shown in Fig. 8b, indicating a strong gas flaring signal in the characteristic temperature regime of between 1400 and $2500 \mathrm{~K}$. Elvidge et al. (2015) developed a correlation between the VIIRS-derived radiant heat and reported gas flared volumes and derived the relationship:

$V_{\mathrm{a}}=0.0274 \mathrm{RH}^{\prime}\left(R^{2}=0.86\right)$,

where $V_{\mathrm{a}}$ is the annual volume of gas flared (in billion cubic meters) and $\mathrm{RH}^{\prime}$ is the modified radiant heat for each individual flare, adjusted to account for the observed nonlinear relationship between flared gas volume and radiant heat and was computed as $\mathrm{RH}^{\prime}=\sigma T^{4} S^{0.7}$, where $\sigma$ is the StefanBoltzmann constant $\left(5.67 \times 10^{-8} \mathrm{~W} \mathrm{~m}^{-2} \mathrm{~K}^{-1}\right), T$ and $S$ are the source temperature and area, respectively, and the exponent (0.7) was empirically developed by Elvidge et al. (2015) to address nonlinearity. Figure 8a shows the spatial distribution of the cumulative $\mathrm{RH}^{\prime}$ in the study region over the period between January 2019 and June 2020, as aggregated over a $0.05^{\circ} \times 0.05^{\circ}$ grid resolution. To estimate monthly gas flared volumes ( $V_{\mathrm{m}}$ in billion cubic feet) for the study area, we modify the equation above, assuming the relationship holds over monthly intervals:

$V_{\mathrm{m}}=0.0274 \mathrm{RH}^{\prime} \times f / 12$

where $f$ is the conversion between cubic meters and cubic feet $\left(1 \mathrm{~m}^{3}=35.315 \mathrm{ft}^{3}\right)$. We use the equation above to compute the mean monthly gas flared volumes (and $95 \%$ CI on the mean) in the study area based on the daily $\mathrm{RH}^{\prime}$ aggregated from individual detected flares. The trend in the monthly gas flared volumes is shown in Fig. 8c. The average flaring rate in 2019 was $8.2 \pm 2.2 \mathrm{Bcf}$ month $^{-1}\left(2.3 \times 10^{8} \pm 6.2 \times 10^{7} \mathrm{~m}^{3}\right)$. From February 2020, a sharp decline in the mean gas flaring rate was observed, with the lowest estimated flaring rate of $3.2 \pm 0.4 \operatorname{Bcf}\left(9.1 \times 10^{7} \pm 1.1 \times 10^{7} \mathrm{~m}^{3}\right)$ in April. Following a similar procedure for the entire Permian Basin region, the estimated mean monthly flaring rate declined from a mean of $23 \pm 5 \mathrm{Bcf}_{\text {month }}{ }^{-1}\left(6.5 \times 10^{8} \pm 1.4 \times 10^{8} \mathrm{~m}^{3}\right)$ in 2019 to $8.1 \pm 1.7 \mathrm{Bcf}\left(2.3 \times 10^{8} \pm 4.8 \times 10^{7} \mathrm{~m}^{3}\right)$ in May 2020. Thus, the lowest estimated monthly gas flared volumes in 2020 were a factor of 2.6 and 2.8 times lower than the monthly mean observed in 2019 for the $100 \mathrm{~km} \times 100 \mathrm{~km}$ study region and full Permian Basin, respectively.

\section{Appendix B: Aerial flare performance survey}

We compiled a list of potential locations of recently active flares in the Permian Basin (Delaware and Midland subbasins) based on a geospatial analysis of the SkyTruth Global Flaring Dataset, which is derived from heat sources detected by the Visible Infrared Imaging Radiometer Suite (VIIRS) instrument on the NOAA Suomi NPP satellite; SkyTruth has applied several filters to the VIIRS data including removing heat sources $<1500^{\circ} \mathrm{C}$ and with $<3$ detections per month (Skytruth, 2020). To account for spatial uncertainty of SkyTruth flare locations, we spatially joined their individual flare detections between 1 October 2019 and 31 January 2020 using a $100 \mathrm{~m}$ buffer distance; the centroid latitude and longitude of the 1014 joined detections were defined as likely locations of recently active flares. Leak Surveys, Inc. (LSI), a leak detection company specializing in aerial optical gas imaging, was provided a list of 573 potential active flare locations from the original set of 1014 . The site selection methodology balanced representativeness and survey efficiency by defining one contiguous, high flare density area in each subbasin that could be surveyed over the course of approximately $5 \mathrm{~d}$. For the Delaware subbasin, we selected 323 locations located within our main study area (NW and SE corners are $32.325^{\circ} \mathrm{N}, 103.822^{\circ} \mathrm{W}$ and $31.417^{\circ} \mathrm{N}, 103.202^{\circ} \mathrm{W}$, respectively). For the Midland subbasin, we selected 250 locations from the two counties (Midland and Martin) with the highest flare counts from the analysis of VIIRS data. LSI surveyed these locations with a custom infrared camera (IR) deployed in a R44 helicopter. Potential flare locations were identified with spatial coordinates and a unique flare ID.

LSI performed three surveys of the potential flare locations during the weeks of 17 February, 23 March, and 22 June 2020 (EDF, 2020). At each potential flare location, LSI determined if one or more flares was present at the spatial coordinates, and if so, it observed the flare(s) for operational status. For flares with apparent combustion issues, LSI recorded 30-60 s of infrared and visual video footage of the flare plume to provide visual evidence of flare status. For each flare, LSI assigned a qualitative assessment of the apparent flare status at the time of survey from four categories: inactive and unlit with no emissions (inactive); active, lit, and operating properly (operational); active and lit but with operational issues such as incomplete combustion or excessive smoke (malfunction); or active, unlit, and venting methane (unlit). For survey 1, LSI observed 337 flares from the random selection of potential locations. For surveys 2 and 3, a random subset of the 337 flares was selected for resurvey, prioritizing locations that had previously observed issues. We observed similar flare performance in each of the 
three surveys: $11 \%$ of active flares had observed malfunctions, including $5 \%$ that were unlit and venting (Table B1).

To estimate methane emissions from flaring, we used our qualitative flare performance data and conservatively high assumptions about the combustion efficiency of operational, malfunctioning, and unlit flares to estimate overall combustion efficiency, and then we applied combustion efficiency to estimated flared volumes in 2019 based on an analysis of VIIRS data (Appendix B). We assume that operational flares perform at the EPA default combustion efficiency of $98 \%$ (USCFR, 2016). The $5 \%$ of flares that were unlit and venting were assumed to have a combustion efficiency of $0 \%$. The $6 \%$ of flares that were lit with apparent combustion issues were assumed to have $90 \%$ combustion efficiency. If we assume flared gas volumes are proportional to the observed fraction of flares by performance, then the overall combustion efficiency of active flares in the Permian Basin is $93 \%$, which means $7 \%$ of flared methane is emitted. Applying $93 \%$ combustion efficiency to the $280 \mathrm{Bcf}\left(7.9 \times 10^{9} \mathrm{~m}^{3}\right)$ of gas flared in the Permian Basin in 2019 (assuming 80\% $\mathrm{CH}_{4}$ content) results in annual methane emissions of approximately $300000 \mathrm{Mg} \mathrm{CH}_{4}$ from flaring in the Permian Basin; unlit flares account for about $65 \%$ of these emissions, while operational and poorly combusting flares account for about 15 and $10 \%$, respectively. As a sensitivity analysis, we use alternative combustion efficiency assumptions of $90 \%, 50 \%$, and $0 \%$ for operational, malfunctioning, and unlit flares, respectively; this leads to an overall combustion efficiency of $83 \%$ and $2.3 \times$ more flare-related methane emissions that our conservatively low assumptions.

EPA publishes two separate estimates of Permian Basin flaring methane emissions, which incorporates the $98 \%$ combustion efficiency but different gas flared data. The 2020 greenhouse gas inventory (USEPA, 2020a) reports 2018 Permian Basin methane emissions of $12100 \mathrm{MgCH}_{4}$ from associated gas flaring, plus 8500 and $4600 \mathrm{MgCH}_{4}$ from associated gas venting and miscellaneous production flaring, respectively. The Greenhouse Gas Reporting Program (USEPA, 2020b) reports $18800 \mathrm{Mg} \mathrm{CH}_{4}$ from Permian Basin onshore production facilities.
Table B1. The operational performance of Permian Basin flares as observed during three helicopter-based infrared optical gas imaging surveys.

\begin{tabular}{lrrrr}
\hline Surveyed flares & Survey 1 & Survey 2 & Survey 3 & Average \\
\hline Operational & 276 & 147 & 237 & \\
Inactive & 25 & 0 & 62 & \\
Combustion issue & 23 & 9 & 18 & \\
Unlit and venting & 13 & 10 & 12 & \\
\hline Total & 337 & 166 & 329 & \\
\hline Malfunctioning & $11.5 \%$ & $11.4 \%$ & $11.2 \%$ & $11.4 \%$ \\
$\begin{array}{l}\text { (\% of active) } \\
\text { Unlit and venting }\end{array}$ & $4.2 \%$ & $6.0 \%$ & $4.5 \%$ & $4.9 \%$ \\
(\% of active) & & & & \\
\hline
\end{tabular}




\section{Appendix C: Satellite imagery and machine-learning-based estimates of well pad development}

We mapped new well pad construction in the Permian Basin using a two-step machine learning and remote sensing approach. First, well pad candidates were identified in satellite imagery with a convolutional neural network $(\mathrm{CNN})$ model in individual scenes. The model predictions were then compared between the beginning and end of each month to identify the locations of newly constructed well pads. Second, by differencing before and after model outputs, persistent false-positives in the model were removed. The resulting model was deployed on imagery over the Permian Basin on a monthly cadence between 1 August 2019 and 1 July 2020.

We assessed the monthly trends in new well pad construction in the Permian Basin using a combination of satellite imagery from the European Space Agency Sentinel-2 satellite (ESA, 2020) and the National Aeronautics and Space Administration (NASA) Landsat-8 satellite (USGS, 2020). Imagery from Sentinel-2 has a pixel resolution of $10 \mathrm{~m}$, sufficient to clearly identify well pads, and is collected approximately once every $5 \mathrm{~d}$ for any location, providing an average of six collects per month. While this is generally sufficient for monthly monitoring, some areas experience high cloud cover in all the scenes, causing well pads to be missed. Imagery from Landsat- 8 was used to fill in for such cloudy scenes. Despite the slower $16 \mathrm{~d}$ revisit rate and coarser $(30 \mathrm{~m})$ pixel resolution of Landsat- 8 , well pads are still easily detectable. The combined use of these two satellites provided at least one cloud-free scene for all of the Permian Basin for each month within the time period we monitored. We use six spectral bands from both Sentinel-2 and Landsat-8: "red", "green", "blue", "NIR", "SWIR1", and "SWIR2".

New well pad construction was detected in a two-step approach. Well pad candidates were first identified with a convolutional neural network (CNN) model in individual scenes. The model predictions were compared between the beginning and end of each month, and new well pads were identified. Well pads were detected using a semantic segmentation approach. We used a UNet architecture with a six-band input layer with shape (height, width, 12) and output predicting the presence or absence of well pads in each pixel. Landsat8 imagery was resampled to $10 \mathrm{~m}$ to match the resolution of Sentinel-2 imagery.

The model was trained on a ground-truth dataset taken from well pads detected with a separate machine learning model run on high-resolution $(1.5 \mathrm{~m})$ imagery. We generated $\sim 7000$ training tiles, each of size $512 \times 512$ pixels and containing 0 to 400 well pads each. The dataset was split into sets with $70 \%$ for training, $10 \%$ for validation, and $20 \%$ for testing. Examples of image-target pairs are shown in Fig. C1.
New well pads were detected by comparing model output heat maps between the beginning and end of sequential monthly time periods (Fig. C2). Intuitively, pixel values in satellite imagery change frequently in irrelevant ways, so it is more effective to identify change in the model output. The heatmap from the earlier time was subtracted from the later time. A threshold operator followed by a morphological opening operation were applied to these difference maps. New well pad detections were identified in the resulting binary map as shown in Fig. C3.

To further remove false positives, we require that new well pad candidates should not have existed in multiple months leading up to the construction date and should continue to exist for several months after. We thus used the 3 months before and the 2 months after to remove candidates that fail this condition. While the $10 \mathrm{~m}$ resolution of the imagery makes it difficult to confirm with certainty that candidates contain oil and gas infrastructure, we suspect that the Permian Basin region is unlikely to experience a high volume of unrelated ground clearing for development. We confirm this with manual inspection; see details below.

The CNN and change detection pipeline was run over the Permian Basin on monthly imagery composites between 1 August 2019 to 1 July 2020. The deployment was done using the Descartes Labs platform. Tiled imagery was drawn on the fly, model inference was performed in a cloud-native Kubernetes infrastructure, and results were stored in the commercial cloud. Finally, the authors manually verified the candidates for each month.

The change detection analysis has a precision of $\sim 100 \%$, since the final results have been manually verified. It is infeasible to measure the model accuracy or recall directly, as these would require identifying a substantial number of newly constructed well pads as well as false negatives (newly constructed well pads that were missed by the model), which would require extensive manual labeling; additionally, the model performance may vary across geographies, making a single metric less useful. Instead, we estimated the recall using a dataset of well pads identified with a separate machine learning model in high-resolution imagery; we measured the fraction of these well pads that are detected as well pads by the UNet in single mosaics. Any well pads missed in this step will not be identified as new well pads. We measured this recall on four separate monthly mosaics, and found a recall of $90.0 \%$, with a statistical uncertainty of less than a percent. Finally, the number of newly constructed well pads per month are shown in Fig. 7 with examples presented in Figs. C4 and C5. 


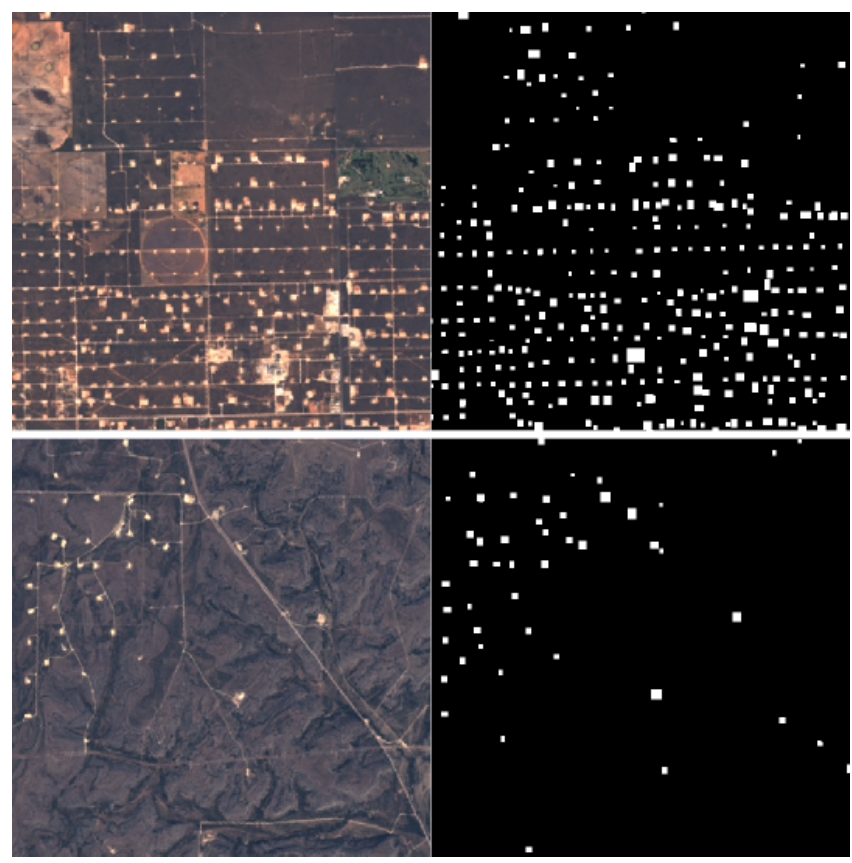

Figure C1. Examples of image-target pairs: (left) Sentinel-2 RGB imagery (ESA, 2020) and (right) ground truth.
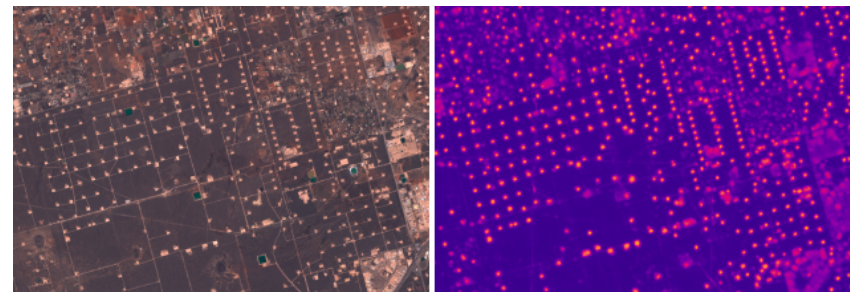

Figure C2. CNN model example, showing Sentinel-2 imagery (left; ESA, 2020) and model output heatmap over the same area (right).

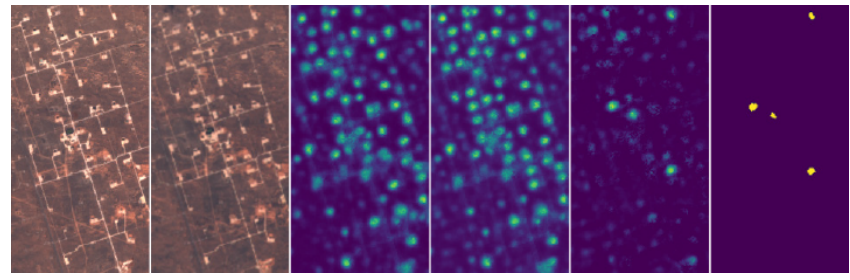

Figure C3. Left to right: before (1) and after (2) medium-resolution imagery (ESA, 2020); same area in model output: (3) before, (4) after, (5) difference, and (6) detected new well pads.

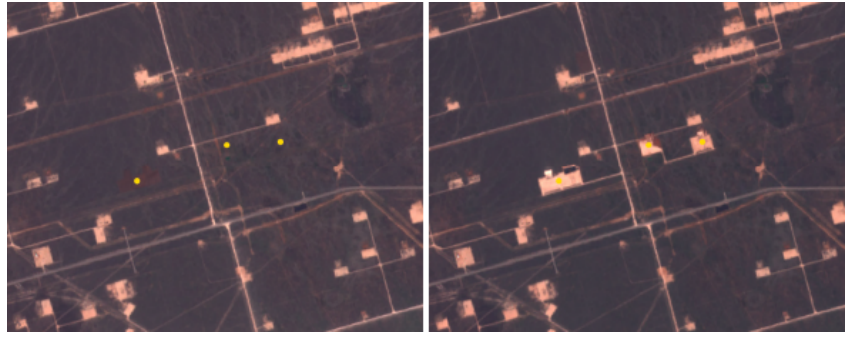

Figure C4. Example of an area where new development was found, before (left) and after (right) shown in Sentinel-2 imagery (ESA, 2020). Points in yellow indicate the locations of new well pad development. 


\section{Appendix D: Well completion emission estimates}

Well completion flowback refers to the unconventional well development period following hydraulic fracturing in which water, proppant, and entrained natural gas flow out of the wellbore to prepare a well for production (Allen et al., 2013). As of 2015, US federal regulations require all oil and gas wells except exploratory and low-pressure wells to utilize reduced emission completions (RECs), which separate the natural gas and send to a pipeline as soon as technically feasible (USEPA, 2019); occasionally, flaring or a combination of REC and flaring is used to partially control emissions. Previous research has demonstrated that RECs control flowback emissions by an average of $99 \%$ (Allen et al., 2013). To estimate monthly completion-related methane emissions within our $100 \mathrm{~km} \times 100 \mathrm{~km}$ study area during the study period, we compiled a list of every well located within our study area with a completion date between 1 January and 30 April 2020 (Enverus, 2021) and applied two approaches to estimate potential and actual emissions. The first approach estimated actual emissions by applying an emission factor (total methane emitted per well completion) based on 2018 data from 3359 completions in the Permian Basin reported to the EPA Greenhouse Gas Reporting Program, which operators estimate with a choice of measurements or engineering equations (USEPA, 2019, 2020b). To convert total emissions into an hourly emission rate, we assumed that completions emit at a constant rate over $4 \mathrm{~d}$, the average duration from Allen et al. (2013). The second approach, which estimated potential emissions, assumes that wells emit their initial gas production for $4 \mathrm{~d}$ following the completion date; we assumed $80 \%$ methane content of natural gas and used the daily average production rate from the first complete month of gas production (referred to as PracIP by Enverus, 2021).
The number of monthly well completions in the study area dropped from 188 in January to 115 in April and then to a minimum of 29 in June 2020 (Table D2). Based on our first approach, January and April 2020 completion-related actual emissions were 3.6 and $2.2 \mathrm{MgCH}_{4} \mathrm{~h}^{-1}$, respectively, with an average emission factor of $19 \mathrm{~kg} \mathrm{CH}_{4} \mathrm{~h}^{-1}$ per completion and $93 \%$ of completions utilizing a REC or REC plus flaring (Table D1). Based on the second approach, the average potential emission rate per completion was $2.0 \mathrm{MgCH}_{4} \mathrm{~h}^{-1}$ in January and $1.7 \mathrm{MgCH}_{4} \mathrm{~h}^{-1}$ in April 2020; this results in total study area completion-related emissions of 45 and $26 \mathrm{Mg} \mathrm{CH}_{4} \mathrm{~h}^{-1}$ in January and April, respectively (Table D2).

Table D1. Estimate of Permian Basin well completion emission factors based on US EPA Greenhouse Gas Reporting Program data.

\begin{tabular}{lrrrr}
\hline & $\begin{array}{r}\text { Permian Basin } \\
\text { annual completions } \\
\text { (no.) }\end{array}$ & $\begin{array}{r}\text { Total methane } \\
\text { emissions } \\
\left(\mathrm{Mg} \mathrm{CH}_{4}\right)\end{array}$ & $\begin{array}{r}\text { Average emissions } \\
\left(\mathrm{Mg} \mathrm{CH}_{4} \text { completion }^{-1}\right)\end{array}$ & $\begin{array}{r}\text { Average emission rate } \\
\text { assuming 4 d duration } \\
\left(\mathrm{kg} \mathrm{CH}_{4} \text { completion }^{-1}\right)\end{array}$ \\
\hline Reduced emission completion (REC) & 1162 & 376 & 0.3 & 3 \\
REC and flared & 1955 & 4673 & 2.4 & 25 \\
Uncontrolled & 14 & 35 & 2.5 & 26 \\
Flared & 228 & 1202 & 5.3 & 55 \\
\hline Total & 3359 & 6287 & 1.9 & 19 \\
\hline
\end{tabular}


Table D2. Estimate of average monthly potential completion-related emissions from our study area from January 2019-September 2020 based on initial gas production data and the assumption of $4 \mathrm{~d}$ completion duration.

\begin{tabular}{rrrr}
\hline Year & Month & $\begin{array}{r}\text { Average ongoing daily well } \\
\text { completions (wells) }\end{array}$ & $\begin{array}{r}\text { Average aggregate completion-related } \\
\text { emissions }\left(\mathrm{Mg} \mathrm{CH}_{4} \mathrm{~h}^{-1}\right)\end{array}$ \\
\hline 2019 & 1 & 13 & 24 \\
2019 & 2 & 21 & 43 \\
2019 & 3 & 17 & 39 \\
2019 & 4 & 23 & 43 \\
2019 & 5 & 18 & 37 \\
2019 & 6 & 18 & 35 \\
2019 & 7 & 23 & 44 \\
2019 & 8 & 25 & 50 \\
2019 & 9 & 16 & 40 \\
2019 & 10 & 22 & 42 \\
2019 & 11 & 26 & 52 \\
2019 & 12 & 20 & 43 \\
2020 & 1 & 22 & 45 \\
2020 & 2 & 24 & 47 \\
2020 & 3 & 22 & 34 \\
2020 & 4 & 15 & 26 \\
2020 & 5 & 5 & 10 \\
2020 & 6 & 4 & 9 \\
2020 & 7 & 8 & 19 \\
2020 & 8 & 8 & 12 \\
\hline
\end{tabular}


Appendix E: Oil and gas production data and assessment of database completeness

Production quantities of oil and gas from individual wells are reported to public state databases (RRC, 2020; NMOCD, 2020); however, the best results are achieved by analyses from an external database (Enverus, 2021), which filters and aggregates all of the publicly available datasets from all reporting agencies. Oil and natural gas production data from New Mexico are updated on a monthly cadence, while data from Texas are updated twice each month but still only at monthly resolution. Time series of oil and natural gas production within the greater Permian Basin and $100 \mathrm{~km} \times 100 \mathrm{~km}$ study area are presented in Fig. E1. Similarly, Fig. E2 presents a time series of the number wells reporting production each month within the basin and $100 \mathrm{~km} \times 100 \mathrm{~km}$ study area as well as time series of the number of wells exhibiting their first month of oil and natural gas production and their as their spud date: the date at which the subsurface drilling commences within the process of well development. The typical lag in data reporting is at least 3 months (Enverus, 2021) (e.g., oil and natural gas production data during the month of June are available on or shortly after the 1 September); however, in practice reporting delays upwards of 6 months have been observed. The draft version of this article included an assessment of the database completeness for incomplete production. At the time of revised manuscript submission (March 2021), we suspect the production database is complete through 31 August 2020 for the data presented in this article and therefore no longer anticipate the need to estimate the database completeness. 

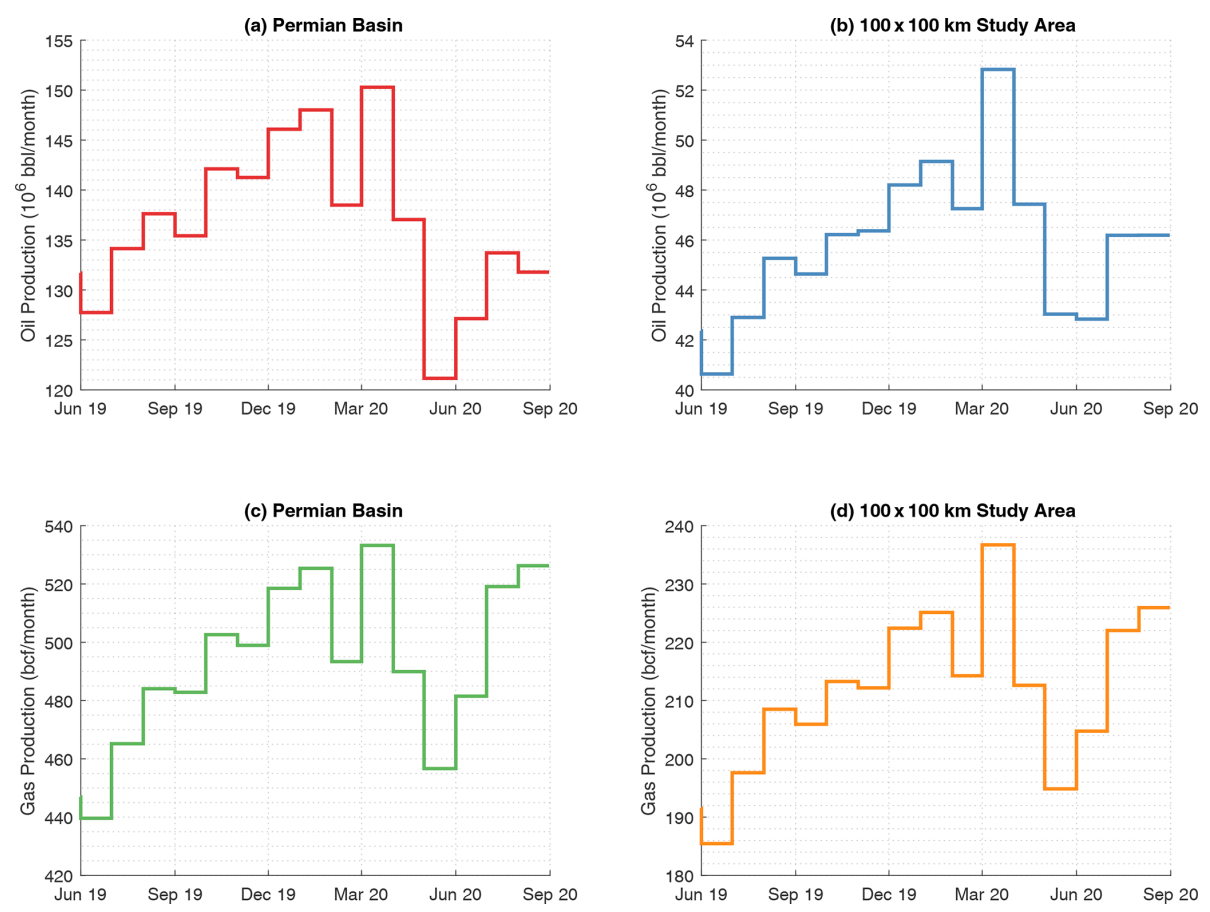

Figure E1. Monthly time series of oil (a, b) and natural gas $(\mathbf{c}, \mathbf{d})$ production in both the Permian Basin $(\mathbf{a}, \mathbf{c})$ and the $100 \mathrm{~km} \times 100 \mathrm{~km}$ study area $(\mathbf{b}, \mathbf{d})\left(\right.$ Enverus, 2021). 1 billion cubic feet $(\mathrm{Bcf})=2.8 \times 10^{7} \mathrm{~m}^{3} ; 1$ barrel of oil $(\mathrm{bbl})=159 \mathrm{~L}$.
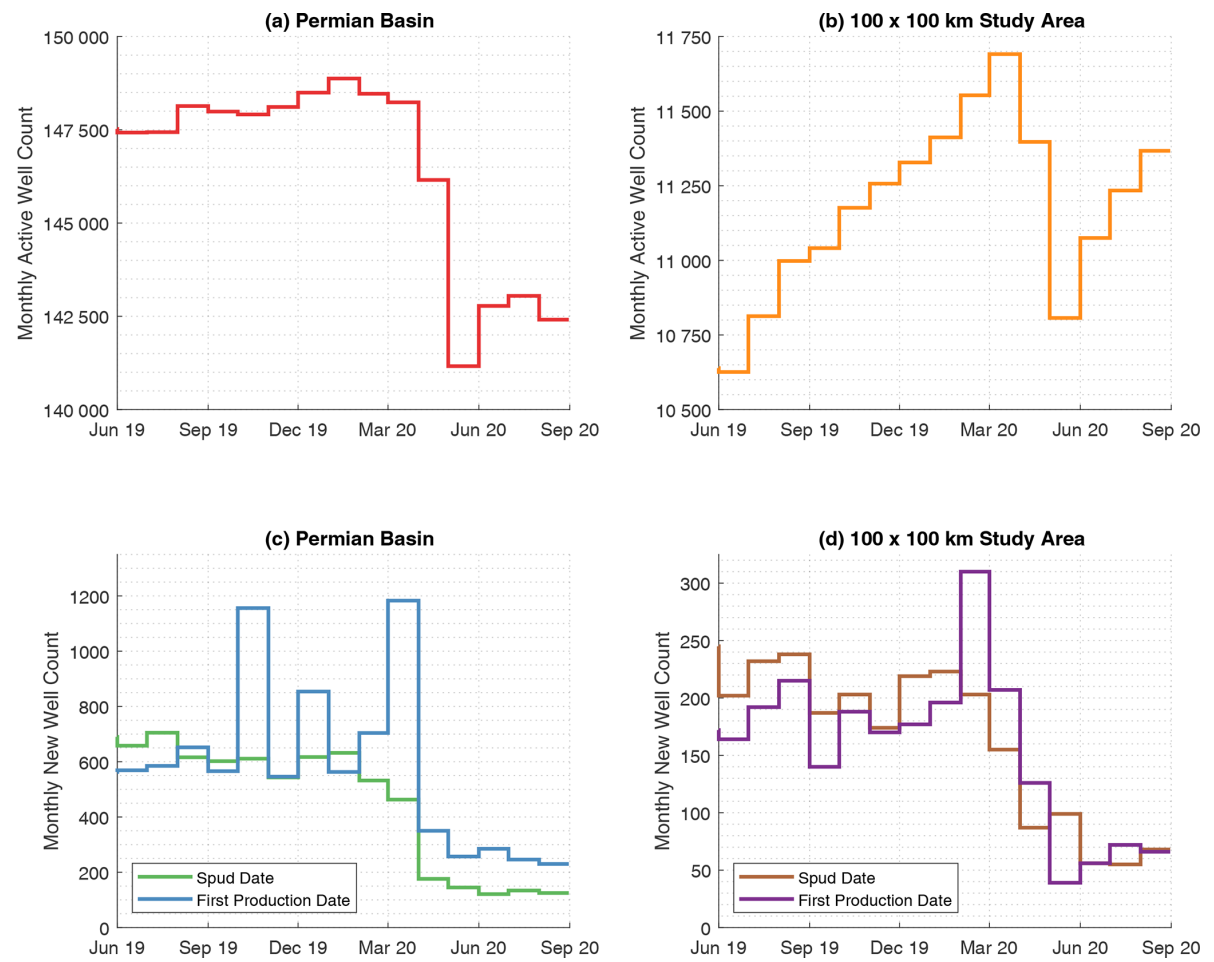

Figure E2. Monthly time series of active wells $(\mathbf{a}, \mathbf{b})$ and newly produced wells by spud date and month of first production $(\mathbf{c}, \mathbf{d})$ in both the Permian Basin (a, c) and the $100 \mathrm{~km} \times 100 \mathrm{~km}$ study area (b, d) (Enverus, 2021). 
Appendix F: Supplementary data from Bakken Shale formation

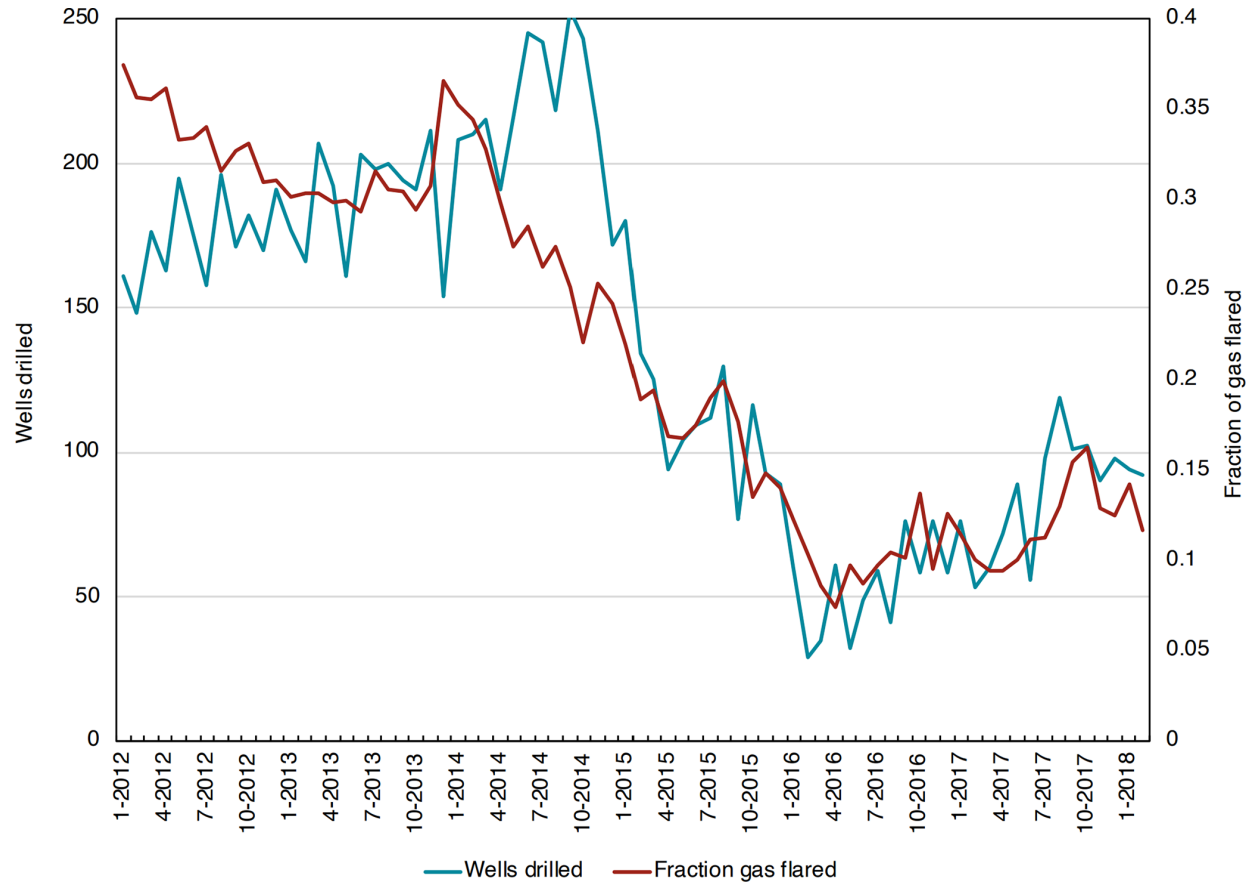

Figure F1. Number of wells drilled versus fraction of total gas production flared in the Bakken region (North Dakota, USA) from $2012-2017$. Similar to trends observed in the Permian, there was a strong correlation between wells drilled and fraction of gas flared with both values decreasing rapidly when oil prices crashed in 2014. 
Data availability. Data are available for download at https://www. permianmap.org/ (EDF, 2020). The data are freely available for noncommercial use, but users are required to submit an email address before they download. To request a download link, click "Explore the Data", click on the "Download Datasets" tab, and then submit an email address in the form to receive a direct download link.

Author contributions. DRL, BH, ARB, MK, EAK, AJM, and SPH contributed to study conceptualization. DRL, BH, RG, MO, KR, ZRB, KJD, NLM, VCM, SJR, SC, MLS, DJJ, LS, DVV, AD, XR, NS, and KTS contributed to methods development and data analysis. DRL, BH, MO, ZRB, KJD, MLS, DJV, and KTS wrote the original draft and all authors reviewed and edited the article.

Competing interests. Adam R. Brandt, Eric A. Kort, Mary Kang, and Anthony J. Marchese serve on the PermianMAP scientific advisory panel. Authors declare no other competing interests.

Acknowledgements. The authors thank Beth Trask, Colin Leyden, Jon Goldstein, Louise White, Caleb Berman, and the entire PermianMAP team for their contribution to the project. We are grateful to Ramon Alvarez, Maureen Lackner, Ricardo Esparza, Ilse Aben, and Bram Maasakkers for providing comments. We are grateful to Niall Armstrong for piloting the research aircraft and Leak Surveys, Inc. for performing the flare performance surveys. The PermianMAP project, which includes the aerial, tower, and flare survey data, is grateful for the support of Bloomberg Philanthropies, Grantham Foundation for the Protection of the Environment, High Tide Foundation, the John D. and Catherine T. MacArthur Foundation, and Quadrivium. Computations for this research were performed on The Pennsylvania State University's Institute for Computational and Data Sciences' Roar supercomputer. We thank Carlsbad Caverns National Park for hosting a methane instrument used in the tower analysis.

Financial support. The PermianMAP project has been supported by Environmental Defense Fund and its donors; the work at Harvard University was supported by NASA Carbon Monitoring System.

Review statement. This paper was edited by Bryan N. Duncan and reviewed by two anonymous referees.

\section{References}

Allen, D. T.: Methane emissions from natural gas production and use: reconciling bottom-up and top-down measurements, Curr. Opin. Chem. Eng., 5, 78-83, https://doi.org/10.1016/j.coche.2014.05.004, 2014.

Allen, D. T., Torres, V. M., Thomas, J., Sullivan, D. W., Harrison, M., Hendler, A., Herndon, S. C., Kolb, C. E., Fraser, M. P., Hill, A. D., Lamb, B. K., Miskimins, J., Sawyer, R. F., and Seinfeld, J. H.: Measurements of methane emissions at natural gas pro- duction sites in the United States, P. Natl. Acad. Sci. USA, 110, 17768-17773, https://doi.org/10.1073/pnas.1304880110, 2013.

Alvarez, R. A., Pacala, S. W., Winebrake, J. J., Chameides, W. L., and Hamburg, S. P.: Greater focus needed on methane leakage from natural gas infrastructure, P. Natl. Acad. Sci. USA, 109, 6435-6440, https://doi.org/10.1073/pnas.1202407109, 2012.

Alvarez, R. A., Zavala-Araiza, D., Lyon, D. R., Allen, D. T., Barkley, Z. R., Brandt, A. R., Davis, K. J., Herndon, S. C., Jacob, D. J., Karion, A., Kort, E. A., Lamb, B. K., Lauvaux, T., Maasakkers, J. D., Marchese, A. J., Omara, M., Pacala, S. W., Peischl, J., Robinson, A. L., Shepson, P. B., Sweeney, C., Townsend-Small, A., Wofsy, S. C., and Hamburg, S. P.: Assessment of methane emissions from the U.S. oil and gas supply chain, Science, 109, 6435-6440, https://doi.org/10.1126/science.aar7204, 2018.

Apituley, A., Pedergnana, M., Sneep, M., Veefkind, J. P., Loyola, D., and Hasekamp, O.: Sentinel-5 precursor/TROPOMI Level 2 Product User Manual, Methane, SRON, 2017.

Baker-Hughes: North America Rig Count, Baker Hughes, available at: https://rigcount.bakerhughes.com/na-rig-count (last access: 27 April 2021), 2020.

Barkley, Z. R., Lauvaux, T., Davis, K. J., Deng, A., Miles, N. L., Richardson, S. J., Cao, Y., Sweeney, C., Karion, A., Smith, M., Kort, E. A., Schwietzke, S., Murphy, T., Cervone, G., Martins, D., and Maasakkers, J. D.: Quantifying methane emissions from natural gas production in north-eastern Pennsylvania, Atmos. Chem. Phys., 17, 13941-13966, https://doi.org/10.5194/acp-1713941-2017, 2017.

Barkley, Z. R., Lauvaux, T., Davis, K. J., Deng, A., Fried, A., Weibring, P., Richter, D., Walega, J. G., DiGangi, J., Ehrman, S. H., Ren, X., and Dickerson, R. R.: Estimating Methane Emissions From Underground Coal and Natural Gas Production in Southwestern Pennsylvania, Geophys. Res. Lett., 46, 45314540, https://doi.org/10.1029/2019gl082131, 2019.

Brandt, A. R., Heath, G. A., Kort, E. A., O’Sullivan, F., Petron, G., Jordaan, S. M., Tans, P., Wilcox, J., Gopstein, A. M., Arent, D., Wofsy, S., Brown, N. J., Bradley, R., Stucky, G. D., Eardley, D., and Harriss, R.: Methane Leaks from North American Natural Gas Systems, Science, 343, 733-735, https://doi.org/10.1126/science.1247045, 2014.

Conley, S., Franco, G., Faloona, I., Blake, D. R., Peischl, J., and Ryerson, T. B.: Methane emissions from the 2015 Aliso Canyon blowout in Los Angeles, CA, Science, 351, 1317-1320, https://doi.org/10.1126/science.aaf2348, 2016.

Conley, S., Faloona, I., Mehrotra, S., Suard, M., Lenschow, D. H., Sweeney, C., Herndon, S., Schwietzke, S., Pétron, G., Pifer, J., Kort, E. A., and Schnell, R.: Application of Gauss's theorem to quantify localized surface emissions from airborne measurements of wind and trace gases, Atmos. Meas. Tech., 10, 33453358, https://doi.org/10.5194/amt-10-3345-2017, 2017.

Dlugokencky, E. J., Myers, R. C., Lang, P. M., Masarie, K. A., Crotwell, A. M., Thoning, K. W., Hall, B. D., Elkins, J. W., and Steele, L. P.: Conversion of NOAA atmospheric dry air $\mathrm{CH}_{4}$ mole fractions to a gravimetrically prepared standard scale, J. Geophys. Res.-Atmos., 110, D18306, https://doi.org/10.1029/2005jd006035, 2005.

EDF: Permian Methane Analysis Project (PermianMAP), Environmental Defense Fund, available at: https://www.permianmap.org (last access: 27 April 2021), 2020. 
Elvidge, C., Zhizhin, M., Hsu, F.-C., and Baugh, K.: VIIRS nightfire: Satellite pyrometry at night, Remote Sensing, 5, 4423-4449, https://doi.org/10.3390/rs5094423, 2013.

Elvidge, C. D., Zhizhin, M., Hsu, F.-C., Baugh, K., Khomarudin, M. R., Vetrita, Y., Sofan, P., and Hilman, D.: Long-wave infrared identification of smoldering peat fires in Indonesia with nighttime Landsat data, Environ. Res. Lett., 10, 065002, https://doi.org/10.1088/1748-9326/10/6/065002, 2015.

Elvidge, C. D., Zhizhin, M., Baugh, K., Hsu, F.-C., and Ghosh, T.: Methods for Global Survey of Natural Gas Flaring from Visible Infrared Imaging Radiometer Suite Data, Energies, 9, 14, https://doi.org/10.3390/en9010014, 2016.

Enverus: Drillinginfo, available at: https://app.drillinginfo.com/ production, last access: 12 March 2021.

ESA: Sentinel-2 Imagery, available at: https://scihub.copernicus. eu/, last access: 23 August 2020.

Gould, T., McGlade, C., and Schulz, R.: Methane Emissions from Oil and Gas, International Energy Agency, Paris, available at: https://www.iea.org/reports/ methane-emissions-from-oil-and-gas (last access: 21 April 2021), 2020.

Hasekamp, O. P., Gryspeerdt, E., and Quaas, J.: Analysis of polarimetric satellite measurements suggests stronger cooling due to aerosol-cloud interactions, Nat. Commun., 10, 5405, https://doi.org/10.1038/s41467-019-13372-2, 2019.

$\mathrm{Hu}, \mathrm{H} .$, Landgraf, J., Detmers, R., Borsdorff, T., Aan de Brugh, J., Aben, I., Butz, A., and Hasekamp, O.: Toward Global Mapping of Methane With TROPOMI: First Results and Intersatellite Comparison to GOSAT, Geophys. Res. Lett., 45, 3682-3689, https://doi.org/10.1002/2018gl077259, 2018

Jacobs, T.: Ghawar vs. Permian Basin: Is There Even a Comparison?, J. Petroleum Technol., available at: https://pubs.spe.org/ en/jpt/jpt-article-detail/?art=5377 (last access: 29 April 2021), 2019

Karion, A., Sweeney, C., Kort, E. A., Shepson, P. B., Brewer, A., Cambaliza, M., Conley, S. A., Davis, K., Deng, A., Hardesty, M., Herndon, S. C., Lauvaux, T., Lavoie, T., Lyon, D., Newberger, T., Pétron, G., Rella, C., Smith, M., Wolter, S., Yacovitch, T. I., and Tans, P.: Aircraft-Based Estimate of Total Methane Emissions from the Barnett Shale Region, Environ. Sci. Technol., 49, 81248131, https://doi.org/10.1021/acs.est.5b00217, 2015.

Kort, E. A., Frankenberg, C., Costigan, K. R., Lindenmaier, R., Dubey, M. K., and Wunch, D.: Four corners: The largest US methane anomaly viewed from space, Geophys. Res. Lett., 41, 6898-6903, https://doi.org/10.1002/2014gl061503, 2014.

Lucchesi, R.: File Specification for GEOS-5 FP, GMAO Office Note No. 4 (Version 1.0), available at: http://gmao.gsfc.nasa.gov/pubs/ office_notes, 2013.

Lyon, D. R., Alvarez, R. A., Zavala-Araiza, D., Brandt, A. R., Jackson, R. B., and Hamburg, S. P.: Aerial Surveys of Elevated Hydrocarbon Emissions from Oil and Gas Production Sites, Environ. Sci. Technol., 50, 4877-4886, https://doi.org/10.1021/acs.est.6b00705, 2016.

Maasakkers, J. D., Jacob, D. J., Sulprizio, M. P., Turner, A. J., Weitz, M., Wirth, T., Hight, C., DeFigueiredo, M., Desai, M., Schmeltz, R., Hockstad, L., Bloom, A. A., Bowman, K. W., Jeong, S., and Fischer, M. L.: Gridded National Inventory of U.S. Methane Emissions, Environ. Sci. Technol., 50, 13123-13133, https://doi.org/10.1021/acs.est.6b02878, 2016.
Marchese, A. J., Vaughn, T. L., Zimmerle, D. J., Martinez, D. M., Williams, L. L., Robinson, A. L., Mitchell, A. L., Subramanian, R., Tkacik, D. S., Roscioli, J. R., and Herndon, S. C.: Methane Emissions from United States Natural Gas Gathering and Processing, Environ. Sci. Technol., 49, 10718-10727, https://doi.org/10.1021/acs.est.5b02275, 2015.

NMOCD: OCD Geographic Information Systems, New Mexico Oil Conservation Division, available at: https://www.emnrd.state. nm.us/OCD/ocdgis.html (last access: 12 March 2021), 2020.

NOAA: Methane $\left(\mathrm{CH}_{4}\right)$ WMO Scale: available at: https://www. esrl.noaa.gov/gmd/ccl/ch4_scale.html (last access: 27 April 2021), 2015.

OGCI: Methane Intensity Target: available at: https: //oilandgasclimateinitiative.com/action-and-engagement/ provide-clean-affordable-energy/ $\{\#\}$ methane-target,

(last access: 27 April 2021), 2020.

Reed, S. and Krauss, C.: Too Much Oil: How a Barrel Came to Be Worth Less Than Nothing, The New York Times, available at: https://www.nytimes.com/2020/04/20/ business/oil-prices.html (last access: 29 April 2021), 2020.

USCFR: United States Code of Federal Regulations: eCFR Title 40 Section 98.233(n)(5), available at: https://ecfr.io/Title-40/ Section-98.233 (last access 29 April 2021), 2016.

USGS: Landsat 8, United States Geological Survey available at: available at: https://www.usgs.gov/core-science-systems/nli/ landsat/landsat-8, last access: 1 November 2020.

Richardson, S. J., Miles, N. L., Davis, K. J., Lauvaux, T., Martins, D. K., Turnbull, J. C., McKain, K., Sweeney, C., and Cambaliza, M. O. L.: Tower measurement network of in-situ $\mathrm{CO}_{2}, \mathrm{CH}_{4}$, and $\mathrm{CO}$ in support of the Indianapolis FLUX (INFLUX) Experiment, Elem. Sci. Anth., 5, 59, https://doi.org/10.1525/elementa.140, 2017.

Robertson, A., Edie, R., Field, R. A., Lyon, D. R., McVay, R., Omara, M., Zavala-Araiza, D., and Murphy, S. M.: New Mexico Permian Basin Well Pad Methane Emissions are a Factor of 6-13 Times Higher Than US EPA Estimates, Environ. Sci. Technol., 54, 13926-13934, https://doi.org/10.1021/acs.est.0c02927, 2020.

RRC: Production Data, Railroad Commission of Texas, available at: http://webapps.rrc.texas.gov/PDQ/home.do (last access: 29 April 2021), 2020.

Siddans, R.: S5P Mission Performance Centre NPP Cloud [L2_NP_BDx] Readme, European Space Agency, available at: http://sentinel.esa.int/documents/247904/3541451/ Sentinel-5P-Mission-Performance-Centre-NPP-Cloud-Readme (last access: 29 April 2021), 2020.

Skamarock, W. C., Klemp, J. B., Dudhia, J., Gill, D. O., Barker, D. M., Duda, M. G., Huang, X.-Y., Wang, W., and Powers, J. G.: G.: A description of the Advanced Research WRF version 3, NCAR Tech. Note NCAR/TN-475+ STR, 2008.

Skytruth: Global Flaring Map, available at: https://skytruth.org/ viirs/ (last access: 12 March 2021), 2020.

Smith, M. L., Gvakharia, A., Kort, E. A., Sweeney, C., Conley, S. A., Faloona, I., Newberger, T., Schnell, R., Schwietzke, S., and Wolter, S.: Airborne Quantification of Methane Emissions over the Four Corners Region, Environ. Sci. Technol., 51, 5832-5837, https://doi.org/10.1021/acs.est.6b06107, 2017.

USEIA: Henry Hub Natural Gas Spot Price, United States Energy Information Administration, available at: https://www.eia. 
gov/dnav/ng/hist/rngwhhdM.htm (last access: 12 March 2021), 2020a.

USEIA: Cushing, OK WTI Spot Price FOB, United States Energy Information Administration, available at: https://www.eia.gov/ dnav/pet/hist/rwtcD.htm (last access: 12 March 2021), 2020b.

USEPA: Oil and Natural Gas Sector: Emission Standards for New, Reconstructed, and Modified Sources, 107, United States Environmental Protection Agency, 40 CFR Part 60, 2020-18114, available at: https://www.federalregister.gov/documents/2020/09/14/202018114/oil-and-natural-gas-sector-emission-standards-for-newreconstructed-and-modified-sources-review last access: 29 April 2021, 2019.

USEPA: Inventory of U.S. Greenhouse Gas Emissions and Sinks: 1990-2018, United States Environmental Protection Agency, available at: https://www.epa.gov/ghgemissions/ inventory-us-greenhouse-gas-emissions-and-sinks-1990-2018 (last access: 29 April 2021), 2020a.

USEPA: GHG Reporting Program Data Sets: available at: https: //www.epa.gov/ghgreporting/ghg-reporting-program-data-sets (last access: 29 April 2021), 2020b.
Zavala-Araiza, D., Lyon, D., Alvarez, R. A., Palacios, V., Harriss, R., Lan, X., Talbot, R., and Hamburg, S. P.: Toward a Functional Definition of Methane Super-Emitters: Application to Natural Gas Production Sites, Environ. Sci. Technol., 49, 8167-8174, https://doi.org/10.1021/acs.est.5b00133, 2015.

Zavala-Araiza, D., Alvarez, R. A., Lyon, D. R., Allen, D. T., Marchese, A. J., Zimmerle, D. J., and Hamburg, S. P.: Super-emitters in natural gas infrastructure are caused by abnormal process conditions, Nat. Commun., 8, 14012, https://doi.org/10.1038/ncomms14012, 2017.

Zhang, Y., Gautam, R., Pandey, S., Omara, M., Maasakkers, J. D., Sadavarte, P., Lyon, D. R., Nesser, H., Sulprizio, M. P., Varon, D. J., Zhang, R., Houweling, S., Zavala-Araiza, D., Alvarez, R. A., Lorente, A., Hamburg, S. P., Aben, I., and Jacob, D. J.: Quantifying methane emissions from the largest oil-producing basin in the United States from space, Sci. Adv., 6, eaaz5120, https://doi.org/10.1126/sciadv.aaz5120, 2020. 